\title{
Evaluation of Mei-yu heavy-rainfall quantitative precipitation forecasts in Taiwan by a cloud-resolving model for three seasons of 2012-2014
}

\author{
Chung-Chieh Wang ${ }^{1}$, Pi-Yu Chuang ${ }^{1}$, Chih-Sheng Chang ${ }^{1}$, Kazuhisa Tsuboki ${ }^{2}$, Shin-Yi Huang ${ }^{1}$, and Guo-Chen Leu ${ }^{3}$ \\ ${ }^{1}$ Department of Earth Sciences, National Taiwan Normal University, Taipei, Taiwan \\ ${ }^{2}$ Institute for Space-Earth Environmental Research, Nagoya University, Nagoya, Japan \\ ${ }^{3}$ Central Weather Bureau, Taipei, Taiwan
}

Correspondence: Pi-Yu Chuang (giselle780507@ hotmail.com)

Received: 7 December 2020 - Discussion started: 22 February 2021

Revised: 16 November 2021 - Accepted: 22 November 2021 - Published: 5 January 2022

\begin{abstract}
In this study, the performance of quantitative precipitation forecasts (QPFs) by the Cloud-Resolving Storm Simulator (CReSS) in Taiwan, at a horizontal grid spacing of $2.5 \mathrm{~km}$ and a domain size of $1500 \times 1200 \mathrm{~km}^{2}$, in the range of 1-3 d during three Mei-yu seasons (May-June) of 2012-2014 is evaluated using categorical statistics, with an emphasis on heavy-rainfall events ( $\geq 100 \mathrm{~mm}$ per $24 \mathrm{~h}$ ). The categorical statistics are chosen because the main hazards are landslides and floods in Taiwan, so predicting heavy rainfall at the correct location is important. The overall threat scores (TSs) of QPFs for all events on day 1 (0$24 \mathrm{~h}$ ) are $0.18,0.15$, and 0.09 at thresholds of 100, 250, and $500 \mathrm{~mm}$, respectively, and indicate considerable improvements at increased resolution compared to past results and $5 \mathrm{~km}$ models ( $\mathrm{TS}<0.1$ at $100 \mathrm{~mm}$ and $\mathrm{TS} \leq 0.02$ at $250 \mathrm{~mm}$ ).

Moreover, the TSs are shown to be higher and the model more skillful in predicting larger events, in agreement with earlier findings for typhoons. After classification based on observed rainfall, the TSs of day -1 QPFs for the largest $4 \%$ of events by CReSS at 100, 250, and $500 \mathrm{~mm}$ (per 24 h) are $0.34,0.24$, and 0.16 , respectively, and can reach 0.15 at $250 \mathrm{~mm}$ on day $2(24-48 \mathrm{~h})$ and $130 \mathrm{~mm}$ on day $3(48-72 \mathrm{~h})$. The larger events also exhibit higher probability of detection and lower false alarm ratio than smaller ones almost without exception across all thresholds. With the convection and terrain better resolved, the strength of the model is found to lie mainly in the topographic rainfall in Taiwan rather than migratory events that are more difficult to predict. Our results highlight the crucial importance of cloud-resolving ca-
\end{abstract}

pability and the size of fine mesh for heavy-rainfall QPFs in Taiwan.

\section{Introduction}

Quantitative precipitation forecasts (QPFs) are one of the most challenging areas in modern numerical weather prediction (e.g., Golding, 2000; Fritsch and Carbone, 2004; Cuo et al., 2011), especially for extreme events that have high potential for hazards. With its steep and complex topography, Taiwan over the western North Pacific (Fig. 1) experiences extreme rainfall rather frequently, mainly during two periods: the typhoon (July-October) and Mei-yu (May-June) seasons (e.g., Kuo and Chen, 1990; Wu and Kuo, 1999; Jou et al., 2011; Chang et al., 2013). The landslides and flash floods in and near the mountains and flooding over low-lying plains and urban areas are the main hazards (e.g., Wang et al., $2012 b, 2013 b, 2016 b)$. In order to better prepare for these hazards and reduce their impacts, QPFs and their verifications, especially over heavy-rainfall thresholds from large events, are thus very important for Taiwan. Of course, identifying where the model can make significant improvements in QPFs and what approaches are effective to achieve them is also crucial (e.g., Clark et al., 2011).

For the Mei-yu season in Taiwan, earlier studies mainly employed the widely used standard categorical measures (see Sect. 2.4) to evaluate the performance of models such as the Mesoscale Model version 5 (MM5) at thresholds up to $50 \mathrm{~mm}$ per $12 \mathrm{~h}$ (e.g., Chien et al., 2002, 2006; Yang et 

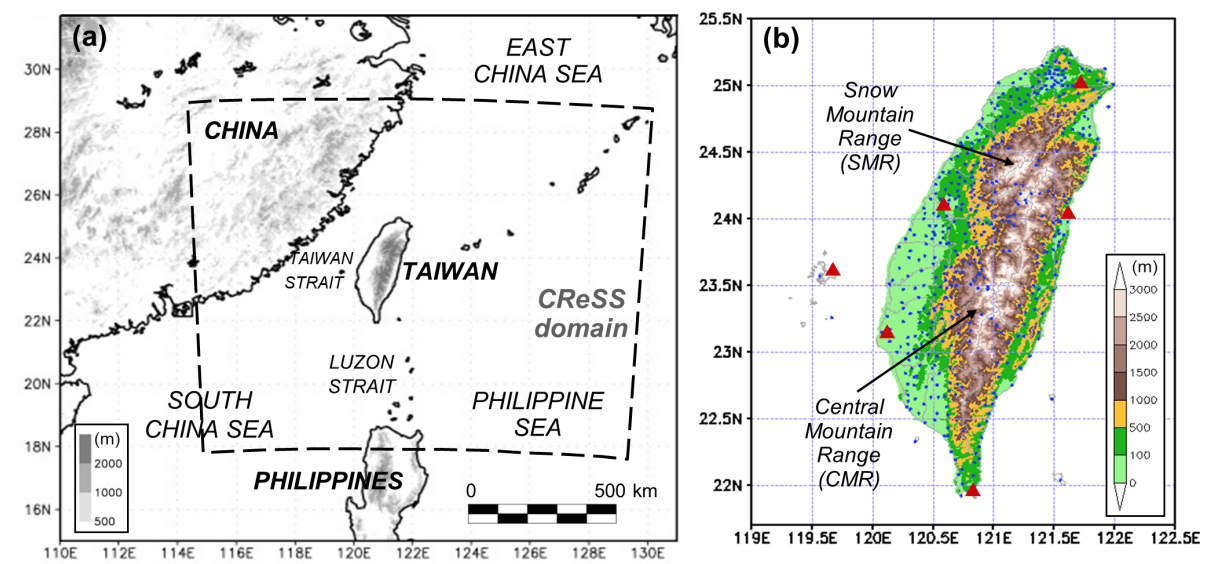

Figure 1. (a) The geography and topography (m; shading) surrounding Taiwan and the domain of $2.5 \mathrm{~km}$ CReSS (thick dashed box) and (b) the detailed terrain of Taiwan ( $\mathrm{m}$; color) and the locations of rain gauges (blue dots) and land-based radars (scarlet triangles) used to produce the reflectivity composites by the Central Weather Bureau (CWB). The two major mountain ranges in Taiwan, the Central Mountain Range (CMR) and Snow Mountain Range (SMR), are marked in (b).

al., 2004). Their results show that the models at the time had some ability to predict rainfall occurrence at thresholds $\leq 2.5 \mathrm{~mm}$ but little skill at $50 \mathrm{~mm}$ and above. In recent years, several studies (e.g., Hsu et al., 2014; Li and Hong, 2014; Su et al., 2016; Huang et al., 2016) have also examined the QPFs by the Weather Research and Forecasting (WRF) model (Skamarock et al., 2005) running at the Central Weather Bureau (CWB) at $5 \mathrm{~km}$ grid spacing $(\Delta x)$, including its ensembles. These studies indicate improvements over earlier models at thresholds up to $50-100 \mathrm{~mm}$ (per $12 \mathrm{~h}$ ) over the previous decade. However, the accuracy at $150-200 \mathrm{~mm}$ and beyond is still limited, even with probability matching (PM; e.g., Ebert, 2001) within the forecast range of $24 \mathrm{~h}$ (see, e.g., Figs. 9 and 10 of Huang et al., 2016).

Figure 2 shows the threat scores (TSs) of day $-1(0$ $24 \mathrm{~h}$ ) and day - 2 (24-48 h) QPFs for May and June of 2013 and 2014 by the CWB models as an example. The TS is defined as the fraction of hits among all verification points that are either observed or predicted, or both, at the specified rainfall threshold, and thus $0 \leq \mathrm{TS} \leq 1$ (further details in Sect. 2.4). The CWB models include deterministic WRF and several products from their 20-member WRF ensemble prediction system (WEPS; e.g., Hong et al., 2015), all with $\Delta x=5 \mathrm{~km}$. These plots have been produced for each month at the CWB for routine verification (within a range of $48 \mathrm{~h}$ ) since 2013 and are similar to those in Huang et al. (2015, 2016). In addition to deterministic forecasts, the scores also include those using PM and new PM (NPM) techniques (e.g., Ebert, 2001; Fang and Kuo, 2013), which may provide some benefit over the ensemble mean (WEPS) for thresholds between 50-200 mm (e.g., Su et al., 2016; Huang et al., 2016). In Fig. 2, one can see that the TSs are no higher than 0.07 at $100 \mathrm{~mm}$ (per $24 \mathrm{~h}$ ) and 0.03 at $200 \mathrm{~mm}$ (and TS $=0$ at and above $300 \mathrm{~mm}$ ) for either day 1 or day 2 in the two Mei-yu seasons, in line with the review above. The scores in June also tend to be lower compared to May, likely due to more events of thermally driven, localized rainfall with low predictability (e.g., Chen and Chen, 2003; Chen et al., 1999; Paul et al., 2018). Nevertheless, effective strategies and methods to improve the skill level at thresholds near $100-150 \mathrm{~mm}$ and beyond are needed.

Wang (2015; hereafter referred to as W15) evaluated the QPFs within $3 \mathrm{~d}$ by a cloud-resolving model (CRM), the Cloud-Resolving Storm Simulator (CReSS; Tsuboki and Sakakibara, 2002, 2007), for all 15 typhoons that hit Taiwan in 2010-2012. With $\Delta x=2.5 \mathrm{~km}$, a grid size more comparable to research studies (e.g., Wang et al., 2005, 2011; 2013a, also Bryan et al., 2003; Done et al., 2004; Clark et al., 2007; Roberts and Lean, 2007), these deterministic forecasts showed superior performance in QPFs, with TSs of 0.38 , 0.32 , and 0.16 at thresholds of 100,250 , and $500 \mathrm{~mm}$, respectively, for all typhoons on day 1 ( $0-24 \mathrm{~h}$; cf. Fig. 13 of W15). Even on day 3 (48-72h), the corresponding TSs are 0.21 , 0.12 , and 0.01 . Thus, the accuracy of QPFs by this CRM over the thresholds of $100-500 \mathrm{~mm}$ is remarkably higher for typhoon rainfall in Taiwan.

Moreover, as summarized in Wang (2016), W15 found a strong positive dependency of categorical scores on overall rainfall amount (which represents event magnitude). That is, the larger the rain, the higher the scores and the better the model performs. For example, the TSs at the same thresholds $(100,250$, and $500 \mathrm{~mm}$ ) for the top five events (roughly top $5 \%$ ) in $\mathrm{W} 15$ on day 1 are $0.68,0.49$, and 0.24 , respectively (Fig. 1 of Wang, 2016), all at least 1.5 times higher than their counterparts for all typhoons. An important implication of this finding is that the model QPFs for extreme events may not be accurately assessed through categorical statistics without proper classification to isolate them from ordinary events, and particularly not by taking the arithmetic mean of TSs of multiple forecasts. The study of W15 also 

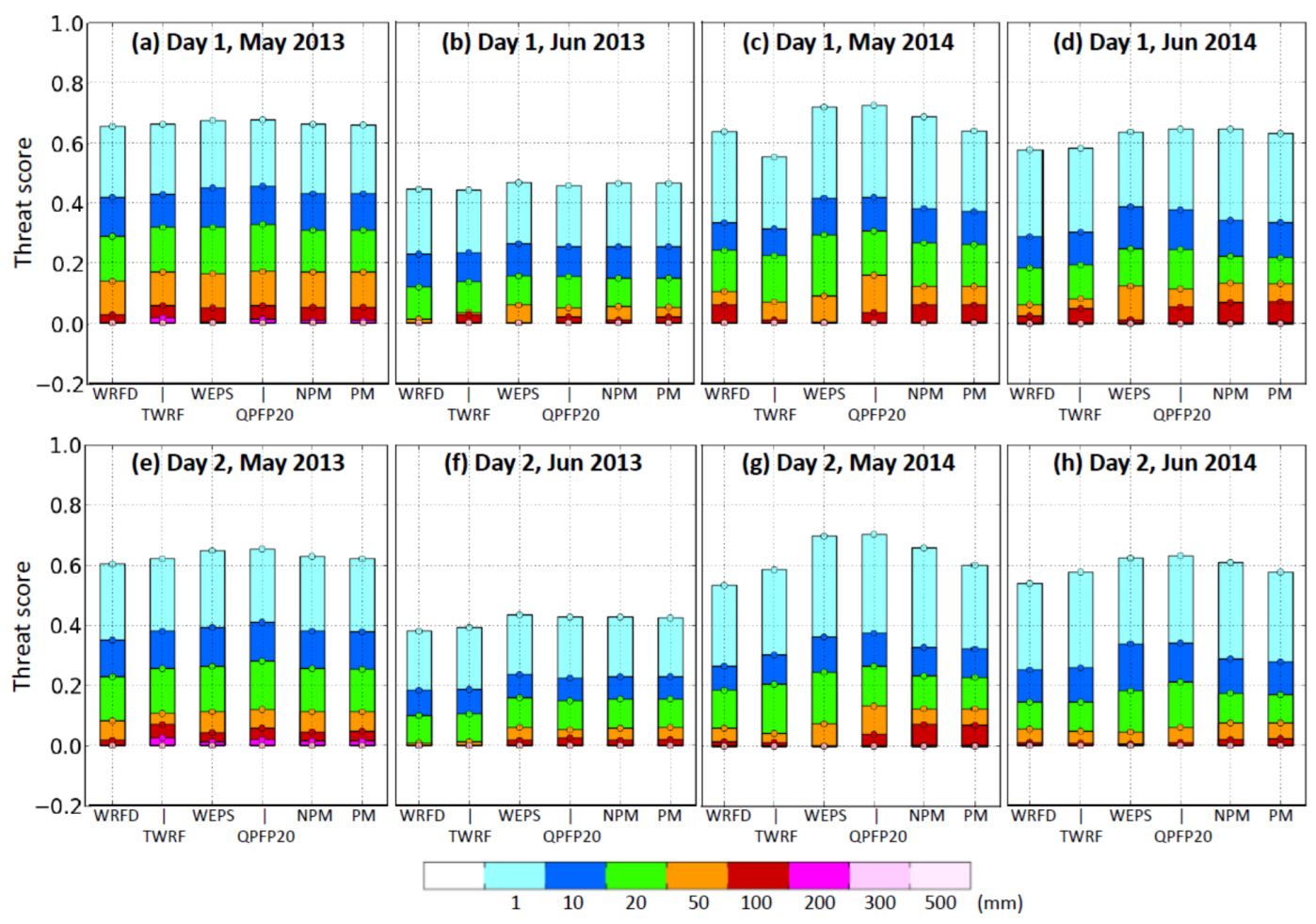

Figure 2. TSs of 0-24h QPFs (day 1) for (a) May and (b) June of 2013 and (c) May and (d) June of 2014, respectively, at selected thresholds over 1-500 mm (per $24 \mathrm{~h}$; scale at bottom) by two deterministic forecasts from WRF (WRFD) and the Typhoon WRF (TWRF) and four ensemble forecasts from the 20-member WRF Ensemble Prediction System: ensemble mean (WEPS), top 20\% (QPFP20), and WEPS employing the probability matching (PM) and new PM (NPM) techniques. (e-h) As in (a)-(d), but showing the TS of 24-48 h QPFs (day 2), respectively.

predicts the dependency, as a fundamental property, to exist in other rainfall regimes. Therefore, the main purpose of this study is threefold: (1) to assess the ability of the $2.5 \mathrm{~km}$ $\mathrm{CReSS}$ in predicting Mei-yu rainfall at a higher resolution than before, especially for heavy to extreme rainfall events; (2) to clarify whether the dependency property in categorical scores also exists in the Mei-yu regime in Taiwan; and (3) to clarify whether the QPFs by CReSS are proven to be improved and why as well as where its strength lies.

In Sect. 2, the model, data, and methodology are described. In Sect. 3, the overall scores of QPFs for groups with different event magnitudes are presented and compared with previous results. Then in Sect. 4, examples are selected to illustrate how the CRM performs in real-time forecasts and where its strength lies. Aspects related to the dependency property are further discussed in Sect. 5, and our conclusions are given in Sect. 6.

\section{Data and methodology}

\subsection{The CReSS model and its forecasts}

The CReSS model is a non-hydrostatic, compressible CRM with a single domain without intermediate nesting (Tsub- oki and Sakakibara, 2002, 2007), and it has been used for weather forecasts in Taiwan since 2006 (http://cressfcst. es.ntnu.edu.tw/, last access: January 2022; W15; Wang et al., 2013b, 2016a). Starting from July 2010, a grid size of $2.5 \mathrm{~km}$ is utilized, with a domain of $1500 \times 1200 \mathrm{~km}^{2}$ since May 2012 (Fig. 1a and Table 1). In CReSS, cloud formation, development, and all related processes are explicitly treated using a bulk cold-rain microphysical scheme with six species (Lin et al., 1983; Cotton et al., 1986; Murakami, 1990; Ikawa and Saito, 1991; Murakami et al., 1994): vapor, cloud water, cloud ice, rain, snow, and graupel (Table 1). Thus, no cumulus (or shallow convection) parameterization is used. Other sub-grid-scale processes parameterized in the model include turbulent mixing in the planetary boundary layer with a 1.5-order closure (Deardorff, 1980; Tsuboki and Sakakibara, 2007) as well as surface radiation and momentum and energy fluxes (Kondo, 1976; Louis et al., 1982; Segami et al., 1989). These physical options are identical to $W 15$ and also given in Table 1.

The operational analyses and forecasts by the Global Forecasting System (GFS; Kanamitsu, 1989; Kalnay et al., 1990; Moorthi et al., 2001; Kleist et al., 2009) of the National Centers for Environmental Prediction (NCEP), produced every $6 \mathrm{~h}$ (at 26 levels), were used as initial and boundary condi- 
Table 1. The basic configuration, initial/boundary conditions (IC/BCs), and physical packages of the $2.5 \mathrm{~km}$ CReSS used for real-time operation in 2012-2014. ${ }^{*}$ The vertical grid spacing of CReSS is stretched (smallest at bottom), and the averaged spacing is given in the parentheses.

\begin{tabular}{|c|c|}
\hline Season & | 2013 and 2014 \\
\hline Projection & Lambert conformal (center at $120^{\circ} \mathrm{E}$, secant at 10 and $40^{\circ} \mathrm{N}$ ) \\
\hline Grid spacing $(\mathrm{km})$ & $2.5 \times 2.5 \times 0.2-0.663(0.5)^{*}$ \\
\hline Grid dimension $(x, y, z)$ & $600 \times 480 \times 40$ \\
\hline Domain size $(\mathrm{km})$ & $1500 \times 1200 \times 20$ \\
\hline Forecast frequency & Every $6 \mathrm{~h}$ (at 00:00, 06:00, 12:00, and 18:00 UTC) \\
\hline Forecast range & $78 \mathrm{~h}$ \\
\hline $\begin{array}{l}\text { IC/BCs (including sea } \\
\text { surface temperature) }\end{array}$ & $\begin{array}{l}\text { NCEP GFS analyses and forecasts (at } 26 \text { levels) } \\
\qquad \mid 0.5^{\circ} \times 0.5^{\circ}\end{array}$ \\
\hline Topography & Real at $(1 / 120)^{\circ}$ spatial resolution $(\sim 0.9 \mathrm{~km})$ \\
\hline Cloud microphysics & $\begin{array}{l}\text { Bulk cold-rain scheme (Lin et al., 1983; Cotton et al., 1986; Murakami, 1990; } \\
\text { Ikawa and Saito, 1991; Murakami et al., 1994) }\end{array}$ \\
\hline $\begin{array}{l}\text { Planetary boundary layer } \\
\text { (PBL) turbulence }\end{array}$ & $\begin{array}{l}\text { 1.5-order closure with prediction of turbulent kinetic energy (Deardorff, 1980; } \\
\text { Tsuboki and Sakakibara, 2007) }\end{array}$ \\
\hline Surface processes & $\begin{array}{l}\text { Energy and momentum fluxes, shortwave and longwave radiation (Kondo, 1976; } \\
\text { Louis et al., 1982; Segami et al., 1989) }\end{array}$ \\
\hline Substrate model & 41 levels, every $5 \mathrm{~cm}$ to $2 \mathrm{~m}$ \\
\hline
\end{tabular}

tions (IC/BCs) for CReSS (Table 1). The CReSS model is also run four times a day, each out to $72 \mathrm{~h}$ (now $78 \mathrm{~h}$ ). At the lower boundary, terrain data at $30^{\prime \prime}$ resolution (roughly $900 \mathrm{~m}$ ) and the NCEP analyzed sea surface temperature are also provided. With its limited domain size, the atmospheric evolution in CReSS is forced by the NCEP forecasts, especially at longer ranges. Note that since 2013, the IC/BCs from the GFS have increased the resolution from $1^{\circ} \times 1^{\circ}$ to $0.5^{\circ} \times 0.5^{\circ}$, but all other settings are kept the same during our study period (Table 1).

\subsection{Data}

The observational data used include synoptic weather maps from the CWB, the vertical maximum indicator reflectivity composites every $30 \mathrm{~min}$ from land-based radars, and hourly rainfall data from about 440 gauges in Taiwan for QPF verification (Fig. 1b). Along with NCEP gridded final analyses (on a $1^{\circ} \times 1^{\circ}$ grid), the weather maps are used to identify and synthesize the occurrence of favorable factors to heavy rainfall among events with different magnitude (to be described in Sect. 2.3). For selected heavy-rainfall cases, the radar composites are compared with the CReSS forecasts to assess the quality of the QPFs in Sect. 4.

\subsection{Verification period classification}

In this study, objective categorical statistics (e.g., Schaefer, 1990; Wilks, 2011) are used to verify QPFs mainly because (1) the ability of models to predict the heavy rainfall at the correct location is imperative in Taiwan since its primary hazards are landslides and floods, and (2) our results can be easily compared with earlier studies. Here, $24 \mathrm{~h}$ QPFs are chosen because (1) the bulk rainfall accumulation from Mei-yu events, as for typhoons, is our main concern rather than the rain over shorter periods, especially at longer ranges (days 2-3), and (2) the issue of double penalty on high-resolution QPFs (e.g., Ebert and McBride, 2000) is less serious using a longer accumulation period. Although the CReSS forecasts are made four times a day, only those from 00:00 and 12:00 UTC are evaluated in this study.

A total of 366 target segments (00:00-24:00 and 12:0012:00 UTC) in May-June 2012-2014 are classified into several groups based on the observed rainfall using the following criteria, as summarized in Table 2. Groups A, B, C, and D are those periods with at least $10 \%$ of rain gauges reaching 50 , $25-50,10-25$, and $1-10 \mathrm{~mm}$, respectively, while group $\mathrm{X}$ is the remaining periods with little or no rain. The full classification results (Table 3 ) give a total of 337 segments, excluding those under typhoon influence. Groups A-D individually account for about $18 \%-26 \%$ and are comparable in sample size, while the driest group, group X, is about $14 \%$ (Tables 2 
and 3). These five groups are exclusive to each other, and the results without classification are referred to as the "all" group. From group A, a subset of A+ that has $\geq 10 \%$ of sites reaching $130 \mathrm{~mm}$ is identified and represents the rainiest $4 \%$ of events in our sample with the highest hazard potential. The spatial distribution of mean Mei-yu rainfall per season in 2012-2014, with a peak amount of about $1700 \mathrm{~mm}$, is shown in Fig. 3 and resembles the climatology (e.g., Yeh and Chen, 1998; Chien and Jou, 2004; Chi, 2006; Wang et al., 2017).

\subsection{Categorical measures of model QPFs}

As mentioned, the $24 \mathrm{~h}$ QPFs by CReSS are verified against the rain gauge data, at three different ranges of $0-24,24-48$, and $48-72 \mathrm{~h}$ (days $1-3$ ). For this purpose, objective scores computed from the standard $2 \times 2$ contingency table (or the categorical matrix) at a wide range of 14 thresholds from 0.05 to $750 \mathrm{~mm}$ are adopted. These measures include the TS (also called critical success index), bias score (BS), probability of detection (POD), and false alarm ratio (FAR), respectively defined as

$\mathrm{TS}=H /(H+M+\mathrm{FA})$,

$\mathrm{BS}=(H+\mathrm{FA}) /(H+M)=F / O$,

$\mathrm{POD}=H /(H+M)=H / O$, and

$\mathrm{FAR}=\mathrm{FA} /(H+\mathrm{FA})=\mathrm{FA} / F$,

where $H, M$, and FA are the counts of hits (both observed and predicted), misses (observed but not predicted), and false alarms (predicted but not observed), respectively, among a total number of $N$ verification points (e.g., Schaefer, 1990; Wilks, 2011; Ebert et al., 2003; Barnes et al., 2009). Here, $N=H+M+\mathrm{FA}+\mathrm{CN}$, where $\mathrm{CN}$ is the correct negatives (neither observed nor predicted), and the total counts in observation $(O)$ and forecast $(F)$ are simply $O=H+M$ and $F=H+$ FA. The values of TS, POD, and FAR are all bounded by 0 and 1 , and the higher (lower) the better for TS and POD (FAR). For BS, its value can vary from 0 to $\infty$ (or $N-1$ in practice), but unity is the most ideal and implies no bias. Also, $\mathrm{BS}>(<) 1$ implies overestimation (underestimation) of the events. By interpolating the model QPFs onto the gauge sites that serve as verification points (i.e., $N \approx 440$ per segment) using the bi-linear method, the counts of $H, M$, $\mathrm{FA}$, and $\mathrm{CN}$ at any given threshold can be easily obtained for each segment. Although the density of rain gauges varies to some extent (roughly every $5-10 \mathrm{~km}$ in the plains and $\geq 10$ $20 \mathrm{~km}$ in the mountains; cf. Fig. 1b), their weights are assumed equal (e.g., Wang, 2014). For any group (e.g., A+) at a given threshold, the scores are obtained from a single $2 \times 2$ table that combines the entries from all segments so that the sample sizes are maximized (cf. Table 2; e.g., W15). This practice also remedies the issue of sampling inhomogeneity and increases the stability of results, especially toward the high thresholds, as long as the points involved in

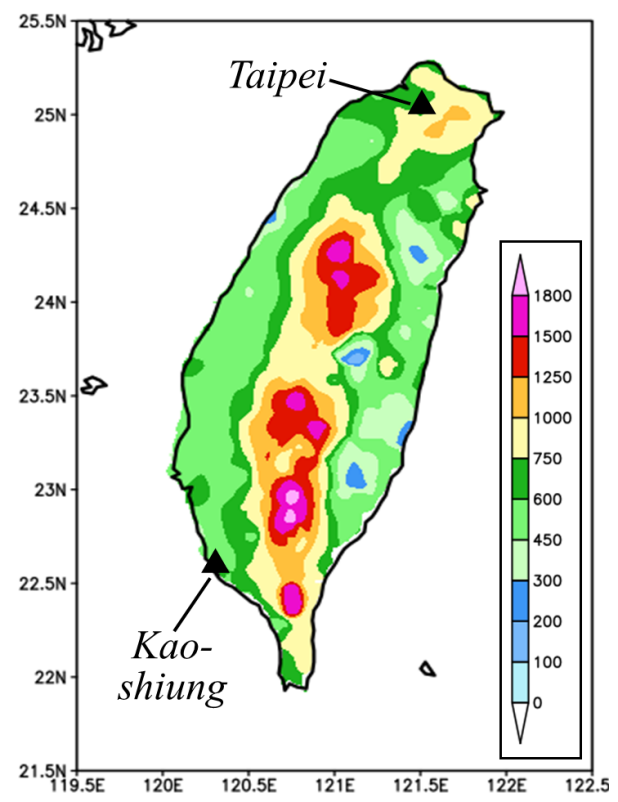

Figure 3. Spatial distribution of mean total rainfall (mm) per Meiyu season (1 May through 30 June) in 2012-2014. The cities of Taipei and Kaohsiung are marked.

the matrix are not too few in number (cf. Table 2). Since neither the observation nor the forecast ever reached $750 \mathrm{~mm}$ (per $24 \mathrm{~h}$ ) during the study period, results for 13 thresholds from 0.05 up to $500 \mathrm{~mm}$ (the next highest threshold) are presented in later sections. Also, only $24 \mathrm{~h}$ QPFs are evaluated in the current study. Except for the categorical matrix, subjective visual verification is also used in the selected examples (Sect. 4).

\section{Mei-yu QPFs in 2012-2014}

\subsection{Overall performance by the $2.5 \mathrm{~km}$ CReSS}

Following the method described above, the categorical matrices across the thresholds are obtained, and the overall ability of CReSS in Mei-yu QPFs during 2012-2014 is shown in Fig. 4 using the performance diagram. Proposed by Roebber (2009), the diagram uses the success ratio $(\mathrm{SR}=1-$ FAR $=H / F)$ and POD as its two axes and can also depict the TS (gray curved isopleths, higher toward upper right) and BS (dotted brown lines) simultaneously. In Fig. 4, the scores from forecasts at both 00:00 and 12:00 UTC for segments (of $24 \mathrm{~h}$ ) in groups $\mathrm{A}+, \mathrm{A}$ to $\mathrm{D}$, and all periods (A-D plus X; cf. Table 2) at 13 thresholds are shown for ranges of day 1,2 , and 3, respectively. The "all" group (black) shows the overall accuracy for all Mei-yu rainfall without classification, and its TS for day -1 QPFs decreases slowly from 0.6 at $0.05 \mathrm{~mm}$ to 0.18 at $100 \mathrm{~mm}, 0.15$ at $250 \mathrm{~mm}$, and 0.09 at $500 \mathrm{~mm}$ (Fig. 4a). Over heavy-rainfall thresholds $\geq 160 \mathrm{~mm}$, the TSs of 0.09-0.16 are considerably higher than those re- 
Table 2. The classification criteria using (at least) 10\% of rain gauges with highest $24 \mathrm{~h}$ accumulated rainfall (00:00-24:00 or 12:0012:00 UTC) over Taiwan and the results in the number of $24 \mathrm{~h}$ segments (and percentage) and total points (sites) of $H+M+$ FA at selected rainfall thresholds $(\mathrm{mm})$ for the different groups. During the Mei-yu seasons of 2012-2014, the total $N$ is 148776 , and on average there are 442 rain gauges per segment. The points of $H+M+$ FA are based on the statistics of day $-1(0-24 \mathrm{~h})$ QPFs, and $N$ is also given (with no threshold).

\begin{tabular}{|c|c|c|c|c|c|c|c|}
\hline \multirow[t]{2}{*}{ Group } & \multirow[t]{2}{*}{$\begin{array}{l}\text { Criterion } \\
\text { (of } 10 \% \text { gauges) }\end{array}$} & \multirow{2}{*}{$\begin{array}{r}\text { No. of } \\
\text { segments } \\
(\%)\end{array}$} & \multirow{2}{*}{$\begin{array}{r}\text { No. of } \\
\text { all points } \\
(N)\end{array}$} & \multicolumn{4}{|c|}{$\begin{array}{c}\text { No. of points }(H+M+\mathrm{FA}) \\
\text { at threshold }(\mathrm{mm})\end{array}$} \\
\hline & & & & 50 & 100 & 250 & 500 \\
\hline $\mathrm{A}+$ & $\geq 130 \mathrm{~mm}$ (a subset of $\mathrm{A})$ & $13(3.9)$ & 5622 & 3807 & 2453 & 490 & 32 \\
\hline A & $\geq 50 \mathrm{~mm}$ & $61(18.1)$ & 26826 & 11000 & 4889 & 675 & 47 \\
\hline B & $\geq 25 \mathrm{~mm}$, but not $\mathrm{A}$ & $75(22.3)$ & 33018 & 4279 & 1078 & 98 & 4 \\
\hline $\mathrm{C}$ & $\geq 10 \mathrm{~mm}$, but not $\mathrm{B}$ & $88(26.1)$ & 38583 & 1675 & 281 & 10 & 3 \\
\hline $\mathrm{D}$ & $\geq 1 \mathrm{~mm}$, but not $\mathrm{C}$ & $67(19.9)$ & 29267 & 266 & 32 & 0 & 0 \\
\hline $\mathrm{X}$ & $<1 \mathrm{~mm}$ & $46(13.6)$ & 20067 & 59 & 20 & 4 & 0 \\
\hline All & A through D plus $X$ & $337(100.0)$ & 147761 & 17279 & 6300 & 787 & 54 \\
\hline
\end{tabular}

Table 3. The full classification result for all the $24 \mathrm{~h}$ verification periods during the three Mei-yu seasons of 2012-2014. For each month, the first (second) row gives the results of 00:00-24:00 (12:00-12:00) UTC. While the groups of A-D and X are denoted by their corresponding letter, a bold A indicates group A+ (a subset of A), and T marks the periods influenced by tropical cyclones and thus excluded from study.

\begin{tabular}{|c|c|c|c|c|c|c|}
\hline \multirow[t]{2}{*}{ Year } & \multirow[t]{2}{*}{ Month } & \multirow{2}{*}{$\begin{array}{l}\text { Time } \\
\text { (UTC) }\end{array}$} & \multicolumn{3}{|c|}{ Date in month } & \multirow{2}{*}{$\begin{array}{l}\text { Segments } \\
\text { included } \\
(\mathrm{A}-\mathrm{D}, \mathrm{X})\end{array}$} \\
\hline & & & $1-10$ & $11-20$ & $21-31$ (or 21-30) & \\
\hline \multirow[t]{4}{*}{2012} & May & 00:00 & XAABDXXXBB & ССXXСВАAАВ & XXDXDCAAABC & 31 \\
\hline & & $12: 00$ & CAADXXXBCC & CXXCBBABAD & XXXXDBAABBD & 31 \\
\hline & June & 00:00 & ССВССССВАА & AAAAABBTTT & TCCDDCTTTD & 23 \\
\hline & & $12: 00$ & DBCDCDBAAA & AАAАВBТTTT & TCDDDTTTTD & 21 \\
\hline \multirow[t]{4}{*}{2013} & May & 00:00 & CCCCBBCCDA & AАCCCABAAA & CBCCCDDDDDX & 31 \\
\hline & & $12: 00$ & CCDCACCDDA & ВВСССАВАВА & BBCCDDDDDXX & 31 \\
\hline & June & 00:00 & ХХCВCCXXCB & BBABCDDDXX & BDBCCXXXXD & 30 \\
\hline & & $12: 00$ & XDBCCDXDCB & BABBDDDXXB & CBBCXXXXXD & 30 \\
\hline \multirow[t]{5}{*}{2014} & May & 00:00 & CCBBBBCCCD & DCBDABXBAA & ADDCDCCBBBC & 31 \\
\hline & & $12: 00$ & CBDABCDCDD & CBDAAXBAAA & BDCCDBBABCD & 31 \\
\hline & June & 00:00 & XDACAABBBC & CTTTTTTDDB & DCBCCDXCAC & 24 \\
\hline & & $12: 00$ & XACBAABBDC & TTTTTTTDBD & CCBCDXDBAC & 23 \\
\hline & Total & \multicolumn{4}{|c|}{ A+: $13, A: 61, B: 75, C: 88, D: 67, X: 46$ (T: 29) } & 337 \\
\hline
\end{tabular}

viewed in Sect. 1. Even on day 2, the TSs remain at 0.11 to 0.06 over $160-500 \mathrm{~mm}$ and above 0.03 up to $350 \mathrm{~mm}$ on day 3 (Fig. 4c and e).

When all segments are stratified by the observed event magnitude, the TSs are higher and the skill better for larger events than smaller ones, following the order of $\mathrm{A}+$ then $\mathrm{A}$ to $\mathrm{D}$ for all thresholds at all three ranges without any exception (Fig. 4), while each individual curve mostly decreases with threshold when rain areas reduce in size (as shown in Fig. 5). Thus, the positive dependency of categorical measures on rainfall amount is also strong and evident in Mei-yu QPFs in Taiwan, as predicted by W15. Linked to this de- pendency, the TSs for large events are also higher than those for the "all" group from the entire sample. For the most hazardous group, group $\mathrm{A}+$, the TS on day 1 is 0.34 at $100 \mathrm{~mm}$, 0.24 at $250 \mathrm{~mm}$, and 0.16 at $500 \mathrm{~mm}$ (per $24 \mathrm{~h}$; Fig. 4a). On days 2 and 3 , the corresponding TSs are $0.32,0.15$, and 0.07 (Fig. 4c) and 0.25, 0.05, and 0.00 (Fig. 4e), respectively, all higher than their counterparts for the "all" group (except day 3 at $500 \mathrm{~mm}$ ). Similar to some earlier studies (e.g., Chien et al., 2002, 2006; Chien and Jou, 2004; Yang et al., 2004) and based on experience, if the value of $\mathrm{TS} \geq 0.15$, perhaps somewhat arbitrary, is used to indicate some level of accuracy, then the QPFs by the $2.5 \mathrm{~km}$ CReSS can reach it all the 

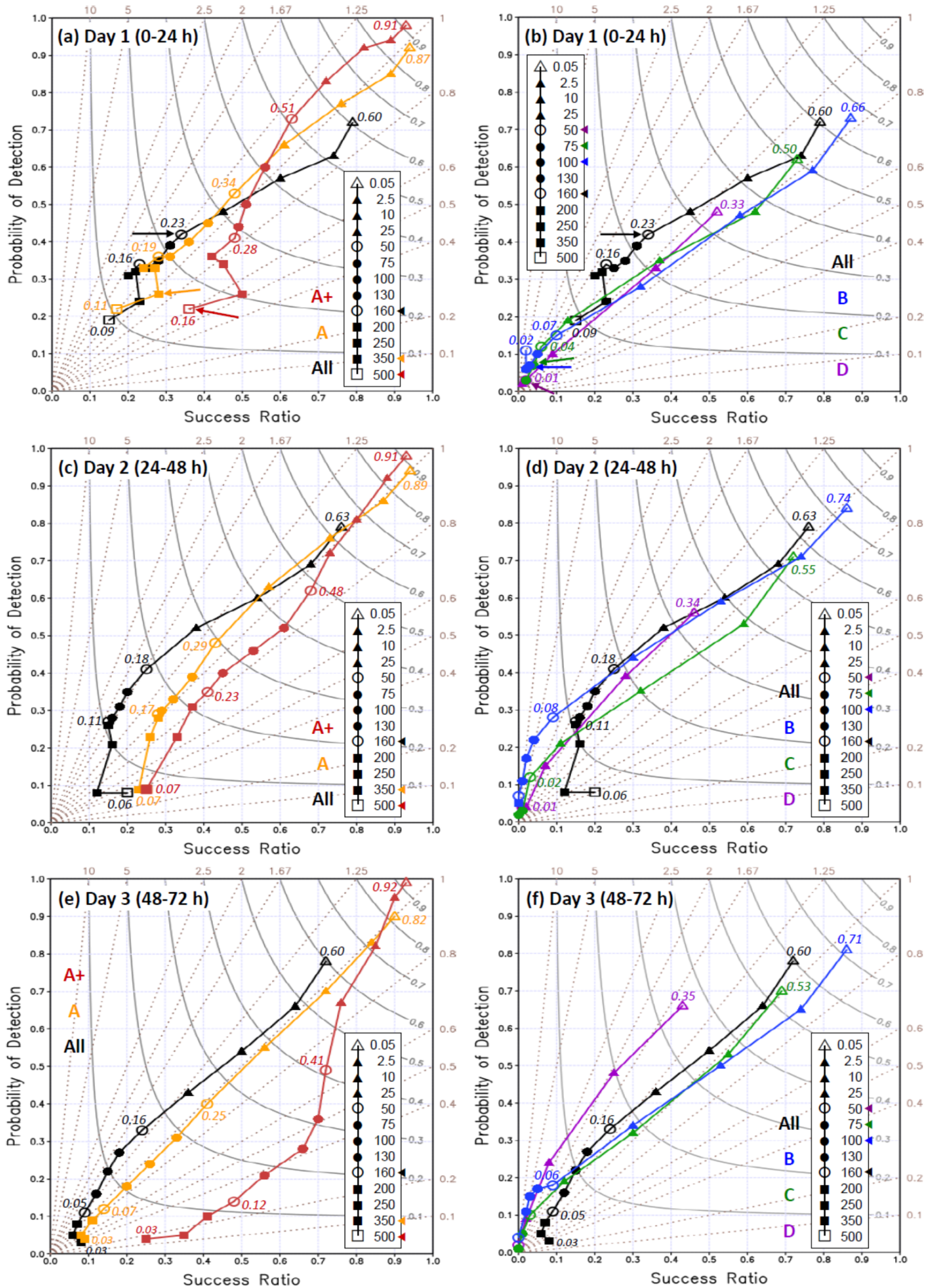

Figure 4. Performance diagrams of $24 \mathrm{~h}$ QPFs for (a, b) day $1(0-24 \mathrm{~h})$, (c, d) day $2(24-48 \mathrm{~h})$, and (e, f) day 3 (48-72 h) by the $2.5 \mathrm{~km}$ CReSS at 13 rainfall thresholds (inserts) from 0.05 to $500 \mathrm{~mm}$ during three Mei-yu seasons (May-June) in 2012-2014 in Taiwan. Results for groups A+, A, and "all" ("all", B, C, and D) are plotted in the left (right) column with different colors. TS values are labeled at fixed thresholds of $0.05,50,160$, and $500 \mathrm{~mm}$ (open symbols) or selected endpoints (smaller fonts), and data points with TS $=0$ at high thresholds are omitted. For each group, the threshold where the observed rain area size $(O / N)$ falls below $1 \%$ is labeled in the insert and also marked by an arrow in $(\mathbf{a}, \mathbf{b})$. 


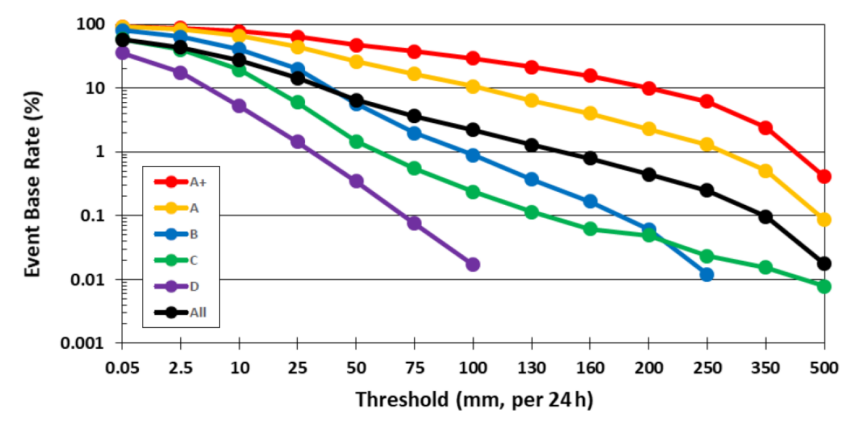

Figure 5. Observed rain area size or base rate $(O / N, \%)$ of $24 \mathrm{~h}$ rainfall (same for days 1-3) in logarithmic scale used to compute the scores in Fig. 4.

way up to $500 \mathrm{~mm}$ (per $24 \mathrm{~h}$ ) on day $1,250 \mathrm{~mm}$ on day 2 , and $130 \mathrm{~mm}$ on day 3. Also, for the A+, A, and "all" groups, the TSs of day -2 QPFs stay quite close to the values on day 1 , and some are even identical, from low thresholds up to $200-250 \mathrm{~mm}$. For day $-3 \mathrm{QPFs}$ compared to day 2, the same is true up to about $130 \mathrm{~mm}$ (Fig. 4, left column). Such results that some skill of heavy-rainfall QPFs still exists on days 2-3 are very encouraging. On the other hand, at thresholds $\geq 50 \mathrm{~mm}$, the model's ability for B-D events (Fig. 4, right column) is limited ( $\mathrm{TS} \leq 0.08$ ) when the rain areas are relatively small (with $O / N \leq 6 \%$; Fig. 5), but as discussed in W15, this is not important due to low hazard potential.

Another fairly subtle but important feature in Fig. 4 is that the TSs of the "all", A, and A+ groups decrease only marginally for some heavy-rainfall thresholds, particularly on days 1-2, despite the reduction in rain area size (left column). Some examples include the TSs for group A+ over $100-350 \mathrm{~mm}$ on day 1 (drops from 0.34 to 0.21 ) and those for group A over the same thresholds on day 1 (from 0.23 to 0.15 ) and over $100-250 \mathrm{~mm}$ on day 2 (from 0.20 to 0.14 ). Even on day 3, the decrease in A and "all" curves from 160 to $350 \mathrm{~mm}$ is rather slow, although the TSs there are only $0.03-$ 0.07 (Fig. 4e). Such a slow decline in TSs with thresholds indicates that in a relative sense, the model is more capable of producing hits toward the rainfall maxima, which occur more frequently in the mountains (cf. Figs. 1b and 3).

By definition, both POD and SR cannot be lower than the TS (cf. Eqs. 1, 3, and 4), and the ratio of POD / SR equals the $\mathrm{BS}$ (thus, $\mathrm{POD}<\mathrm{SR}$ if $\mathrm{BS}<1$ and vice versa). In Fig. 4, the PODs start at $0.05 \mathrm{~mm}$ from nearly perfect values of 0.98-0.99 for days 1-3 for group $\mathrm{A}+$, at least 0.9 for $\mathrm{A}$, and $\geq 0.72$ for all segments (left column). For these three groups, the PODs at $250 \mathrm{~mm}$ remain at least 0.32 on day 1 , 0.21 on day 2 , and 0.05 on day 3 . Like the TS, the POD for Mei-yu rainfall indeed decreases quite significantly with forecast range (lead time), particularly toward high thresholds, mainly due to error growth and the reduction in predictability. However, even on day 3, POD and TS can still reach 0.16 and 0.07 at $130 \mathrm{~mm}$ (for all segments), respec- tively. The SR values (and thus FAR) are again the best for group $\mathrm{A}+$ and $\geq 0.36$ across all thresholds on day 1 , including $500 \mathrm{~mm}$ (Fig. 4a). On day 2, the SRs for A+ over 130$500 \mathrm{~mm}$ decrease but not by too much, and the values over 10-250 mm even increase on day 3 (Fig. 4c and e). Often, the SR for $\mathrm{A}+$ is considerably higher than those for $\mathrm{A}$ and "all" events regardless of forecast range, particularly over heavy-rainfall thresholds. Overall, the model also produces higher POD and SR (i.e., lower FAR) for larger events compared to smaller ones at all thresholds and all three forecast ranges in Fig. 4, with only a few exceptions after close inspection. This indicates that the high-resolution CReSS not only produces larger rainfall for large rainfall events, which leads to a higher TSs, but also produces larger rainfall for small events, which leads to lower SR values. In summary, as for typhoon rainfall (W15), the $2.5 \mathrm{~km}$ CReSS is the most skillful in predicting the largest events in the Mei-yu season in Taiwan.

Next, the BS values are examined for over- and underprediction (i.e., above or below the diagonal line) in Fig. 4, where the threshold with $O / N$ falling below $1 \%$ is marked to indicate values that might be potentially unstable and less meaningful. For day -1 QPFs, the BSs for all segments suggest slight underprediction for low thresholds $\leq 10 \mathrm{~mm}$ (per $24 \mathrm{~h}$ ) but some overprediction $(\mathrm{BS} \approx 1.25-1.5)$ across 50-350 mm (Fig. 4a). In contrast, the model shows slight overprediction over $0.05-75 \mathrm{~mm}$ for the largest events of group $\mathrm{A}+$ (with BSs up to 1.15) but underprediction toward higher thresholds, with the lowest BS of 0.52 at $350 \mathrm{~mm}$. Mostly between the two curves mentioned above, the curve for group A stays closer to unity and is more ideal across nearly all thresholds (Fig. 4a). For B-D groups (Fig. 4b), their characteristics are similar to the "all" group, with BSs of $0.8-1.0$ at low thresholds but generally some overprediction across higher thresholds. However, their BS values rarely exceed 2.5 unless the $O / N$ values drop to below $1 \%$. The situation for BSs between different groups remains similar on days 2 and 3 (Fig. 4c-f), and the over-forecasting across the middle thresholds in group $A$ (at all ranges) can be confirmed to come mainly from groups B-D as groups $\mathrm{A}+$ and A exhibit little or a much less tendency for overprediction there (Fig. 4).

Toward the longer ranges of days 2 and 3, the BS values in general become smaller, particularly for the larger groups (Fig. 4, left column). Thus, the overprediction in group A is reduced, and the underprediction in $\mathrm{A}+$, which is the most important group, becomes more evident, especially toward the high thresholds (Fig. 4c and e). For example, the BS of day -2 QPFs for A+ is ideal and $\geq 0.8$ up to $200 \mathrm{~mm}$ but declines to about 0.35 at $500 \mathrm{~mm}$, but it is already below 0.4 at $130 \mathrm{~mm}$ on day 3 . This indicates that for larger events, the error growth with lead time in the model tends to become less rainy, as reflected in the decrease in BS. Thus, the probability of under-forecasting peak rainfall rises with lead time. For smaller events that do not produce much rainfall (i.e., 
B-D and X), a similar tendency does not exist or is weaker, and BS tends to be greater than unity. So, to say the least, one needs to practice caution in the interpretation of BS, which can also become unstable when $O / N$ approaches zero (which inevitably happens at certain thresholds).

\subsection{Improvement in heavy-rainfall QPFs}

To assess the improvement in heavy-rainfall QPFs in the Mei-yu season, our results in Fig. 4 are compared to Fig. 2 and those reviewed in Sect. 1. However, the differences in model resolution should be noted. Overall, the "all" curves in Fig. 4 indicate that the $2.5 \mathrm{~km}$ CReSS exhibits better skill than those reviewed in Sect. 1 (with $\Delta x$ as fine as $5 \mathrm{~km}$ at most), especially at thresholds above $100 \mathrm{~mm}$ (e.g., $\mathrm{TS}=0.15$ at $250 \mathrm{~mm}$ and 0.09 at $500 \mathrm{~mm}$ for day 1 ). With even higher TSs for larger and more hazardous events (groups A and $\mathrm{A}+$ ), the improvement of heavy-rainfall QPFs in the present study from earlier results is therefore quite clear and dramatic. The physical explanation is further elaborated and discussed later in Sect. 4.

\section{Examples of model QPFs}

Given the success of the CRM in its overall performance, some examples of CReSS forecasts are selected and presented in this section. The main goal here is twofold: (1) to illustrate how the model behaves and captures the rainfall in individual forecasts and thus (2) to identify where such a CRM has a better capability in QPFs and where it has limitations in Taiwan. Since our focus is on heavy rainfall, the event during 9-12 June 2012, the largest during our study period, is chosen for illustration.

The event of 9-12 June 2012 spanned $4 \mathrm{~d}$ and contributes more than half the segments in group A+ (7 in 13; cf. Table 3). In Fig. 6a, the observed $24 \mathrm{~h}$ rainfall distributions over Taiwan are shown every $12 \mathrm{~h}$, from 12:00-12:00 UTC 8 June to 00:00-24:00 UTC 12 June 2012. Except for the first forecast period, all seven segments are qualified as $\mathrm{A}+$, and five have a $24 \mathrm{~h}$ peak rainfall over $500 \mathrm{~mm}$ (those since 12:00 UTC 9 June). Three rainfall maxima from this lengthy event exist: over southern CMR, near the intersection of CMR and SMR in central Taiwan, and over northern Taiwan (Fig. 6a). The rain at the two mountain centers (cf. Fig. 1b) is much more persistent than that in northern Taiwan, which concentrated mainly over a $10 \mathrm{~h}$ period beginning 14:00 UTC 11 June (Wang et al., 2016b). The southwestern plains also received considerable rainfall, especially around 9 June (Fig. 6a).

The $24 \mathrm{~h}$ QPFs produced by the $2.5 \mathrm{~km} \mathrm{CReSS}$ (at 00:00 or 12:00 UTC) in real time targeting the same periods as in Fig. 6a in the range of days 1-3 are presented in Fig. 6b$\mathrm{d}$, with the general quality expressed by the TS at $100 \mathrm{~mm}$ (lower right corner inside panels) and thickened outline for
TS $\geq 0.15$ at the threshold of $50,100,200,350$, or $500 \mathrm{~mm}$. The day -1 QPFs (Fig. 6b) are made from the forecasts starting (with initial time $t_{0}$ ) at the time of the heading, while day -2 (Fig. 6c) and day -3 QPFs (Fig. 6d) are those made 24 and $48 \mathrm{~h}$ earlier (for the same target period), respectively. In Fig. 6, this extreme and long-lasting event was generally well captured by the model, especially on day 1 , where the overall rainfall pattern and TS both tend to be better, as expected. The best day -1 QPF is for 00:00-24:00 UTC 10 June (TS $=0.68$ at $100 \mathrm{~mm}$ and 0.40 at $500 \mathrm{~mm}$ ), followed by the one for 12:00 UTC $11-12$ June (TS $=0.59$ at $100 \mathrm{~mm}$ and 0.29 at $500 \mathrm{~mm}$; columns 4 and 7, Fig. 6b). At longer ranges on days 2 and 3, the rainfall magnitudes produced over the mountains and southwestern plains are also comparable to observations, but the event starts somewhat earlier and becomes less rainy during 10-11 June, showing underforecasting (Fig. 6c and d). As a result, the TSs for the segments starting at 12:00 UTC 8 June and during 10-11 June (columns 1 and 4-7) mostly increase from longer to shorter ranges, i.e., with better QPFs at later times. This relationship with range does not hold true for the other segments, among which the day -3 and day -2 QPFs for the period of 12:00 UTC 9-10 June (TS $\geq 0.51-0.53$ at $100 \mathrm{~mm}$ and $0.20-0.31$ at $350 \mathrm{~mm}$ ) and the day -2 QPF for 12:00 UTC $11-12$ June ( $\mathrm{TS}=0.40$ at $500 \mathrm{~mm}$ ) are particularly impressive (columns 3 and 7). Compared to the rain over the terrain, the maximum across Taipei in northern Taiwan during 11-12 June was largely over lower and flatter regions (cf. Figs. 1b and 2) and more challenging for the model to predict at the right location (Fig. 6), an aspect that is further elaborated on later. Note, nevertheless, that since the mountain regions are the only places where rainfall amounts reach $300 \mathrm{~mm}$ in both the observations and the model (Fig. 6), any hits at and above this threshold occur in the mountains.

Figure 7 shows the TS and BS of day -1 to day -3 QPFs from the runs made at a series of initial times, including 12:00 UTC of 7-9 June and the next four from 00:00 UTC 10 June to 12:00 UTC 11 June (top to bottom), and our focus is mainly over the thresholds $\geq 100 \mathrm{~mm}$. Inside the panels, the observed event base rate $(O / N$, i.e., rain area size, identical at the same threshold for the same target period) and the hit probability $(H / N$; note that $H / N \leq O / N)$ are given at selected points. Figure $7 \mathrm{a}-\mathrm{f}$ provides some examples on how the model did in predicting the beginning of the event (cf. Fig. 6, columns 1-3). As mentioned, the day -3 QPF made from 12:00 UTC 7 June (Fig. 7a and b, blue curves) and day -2 QPF made $1 \mathrm{~d}$ later (Fig. 7c and d, red curves), both targeting 12:00 UTC 9-10 June, are of fairly high quality. With rain areas $(O / N)$ occupying $31 \%, 14 \%$, and just $2 \%$ of Taiwan at 100,200 , and $350 \mathrm{~mm}$, the day $-2 \mathrm{QPF}$ in Fig. $7 c$, with $\mathrm{BS} \approx 0.6-1.1$ (Fig. 7d), yields TSs of 0.53 0.31 at these thresholds. For the day $-3 \mathrm{QPF}$ with $t_{0}$ at 12:00 UTC 7 June, with less predicted rain and $\mathrm{BS} \approx 0.3$ 0.6 (cf. Fig. 6d, column 3), the TSs are 0.51-0.2 (Fig. 7a and b). With a TS of at least 0.2 at $350 \mathrm{~mm}$ (an amount pre- 


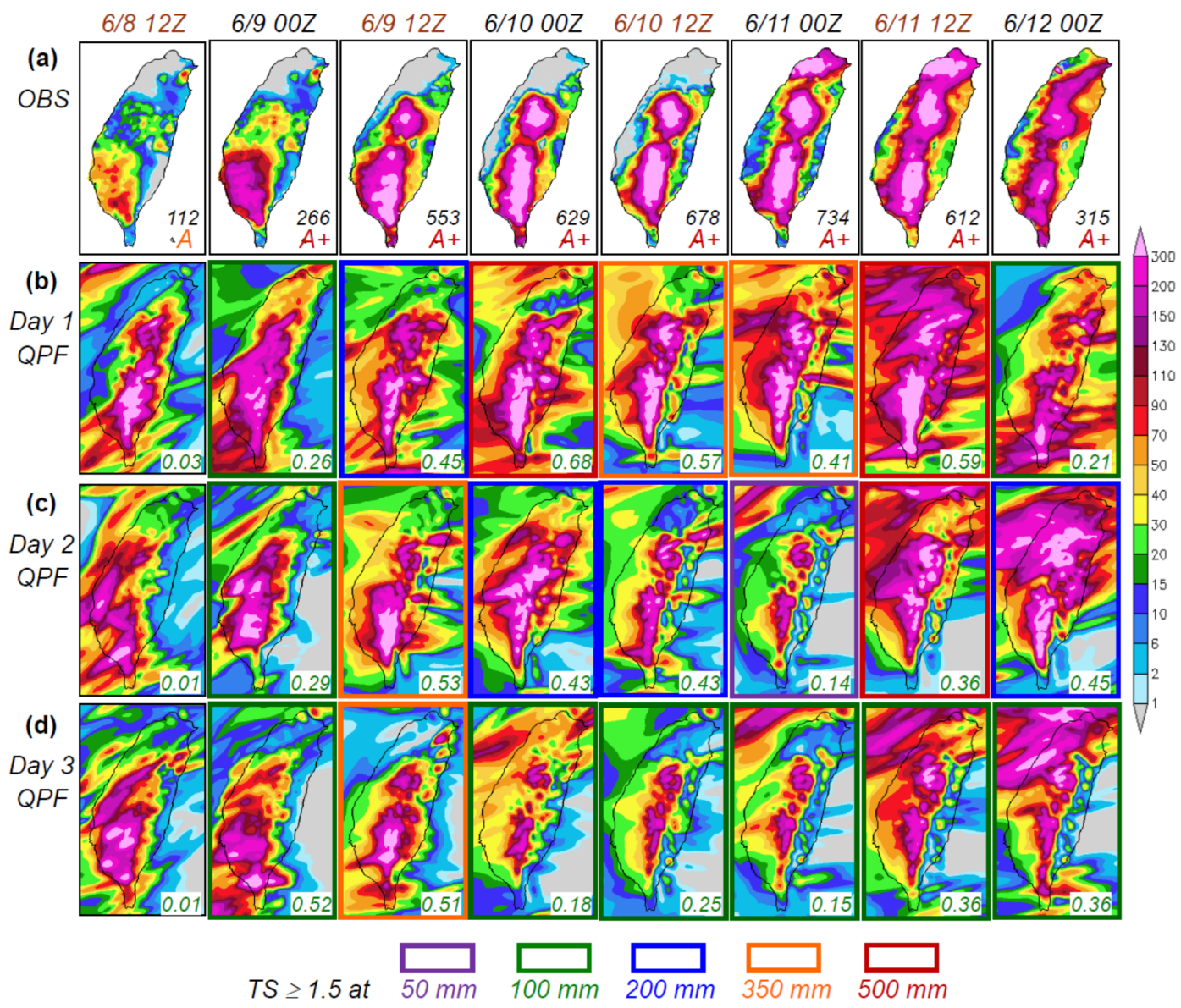

Figure 6. (a) The observed $24 \mathrm{~h}$ accumulated rainfall (mm; scale on the right) over Taiwan from 12:00 UTC 8 June to 00:00 UTC 13 June 2012, given every $12 \mathrm{~h}$ (from left to right), with the beginning time of accumulation (UTC) labeled on top (black for 00:0024:00 UTC and brown for 12:00-12:00 UTC). (b) Day - 1 (0-24 h), (c) day -2 (24-48 h), and (d) day - 3 (48-72 h) QPFs valid for the same $24 \mathrm{~h}$ periods as shown in (a) by the $2.5 \mathrm{~km} \mathrm{CReSS}$ (starting at 00:00 or 12:00 UTC under black or brown headings, respectively). In (a), peak $24 \mathrm{~h}$ rainfall $(\mathrm{mm})$ and classification group are labeled. In (b)-(d), thick boxes in purple, green, blue, orange, and scarlet denote forecasts having a TS $\geq 0.15$ at the threshold of 50,100, 200, 350, and $500 \mathrm{~mm}$ (per $24 \mathrm{~h}$ ), respectively, and the TS at $100 \mathrm{~mm}$ is also given (lower right corner).

dicted only in the southern CMR), both QPFs (for 12:00 UTC 9-10 June) are quite good. Valid for periods with varying magnitude (B, A, and A+), the forecasts in Fig. 7a and b are also good examples to illustrate the dependency property (Fig. 4 and W15), where the rainfall amount apparently exhibits a larger influence on the scores than the forecast range. In Fig. 7e and f, the TS curves at the three ranges (all for $\mathrm{A}+$ events) are closer.

In Fig. 8, the actual forecast near Taiwan between 42 and $69 \mathrm{~h}$, from the run made at 12:00 UTC 7 June, is compared with radar observations every $6 \mathrm{~h}$ to examine general rainfall locations. While a wind-shift line existed off eastern Taiwan, the surface Mei-yu front was well to the north, with prefrontal low-level southwesterly flow impinging on the island during this period (also Wang et al., 2016b). Active convection constantly developed over the mountains in central and southern Taiwan and moved from the upstream ocean into the southwestern plains, and this scenario was well captured by the $2.5 \mathrm{~km}$ CReSS (Fig. 8), yielding a high-quality QPF on day 3 despite some under-forecasting at thresholds $\geq 75 \mathrm{~mm}$ (cf. Fig. 7a and b).

In the four following forecasts made on 10-11 June (Fig. $7 \mathrm{~g}-\mathrm{n}$ ), the dependency on event magnitude exists, but the QPFs made for A+ periods tend to have higher TSs above $75-100 \mathrm{~mm}$ at the shorter ranges (Fig. 7g, i, and k). The TSs of these day -1 QPFs can be as high as 0.48 at $250 \mathrm{~mm}$ and 0.40 at $500 \mathrm{~mm}$. At $350-500 \mathrm{~mm}$, such high TS occurs with $O / N$ below $<10 \%$ (or even only $1 \%$ ) and thus indicates remarkable model accuracy in predicting the peak rainfall at the correct location in the mountains in this event. Over thresholds $\geq 200 \mathrm{~mm}$, BS values in Fig. 7 indicate that underprediction for this extreme event occurs much more often than overprediction, while they also tend to be closer to unity (with less under-forecasting) for QPFs achieving higher TSs. 

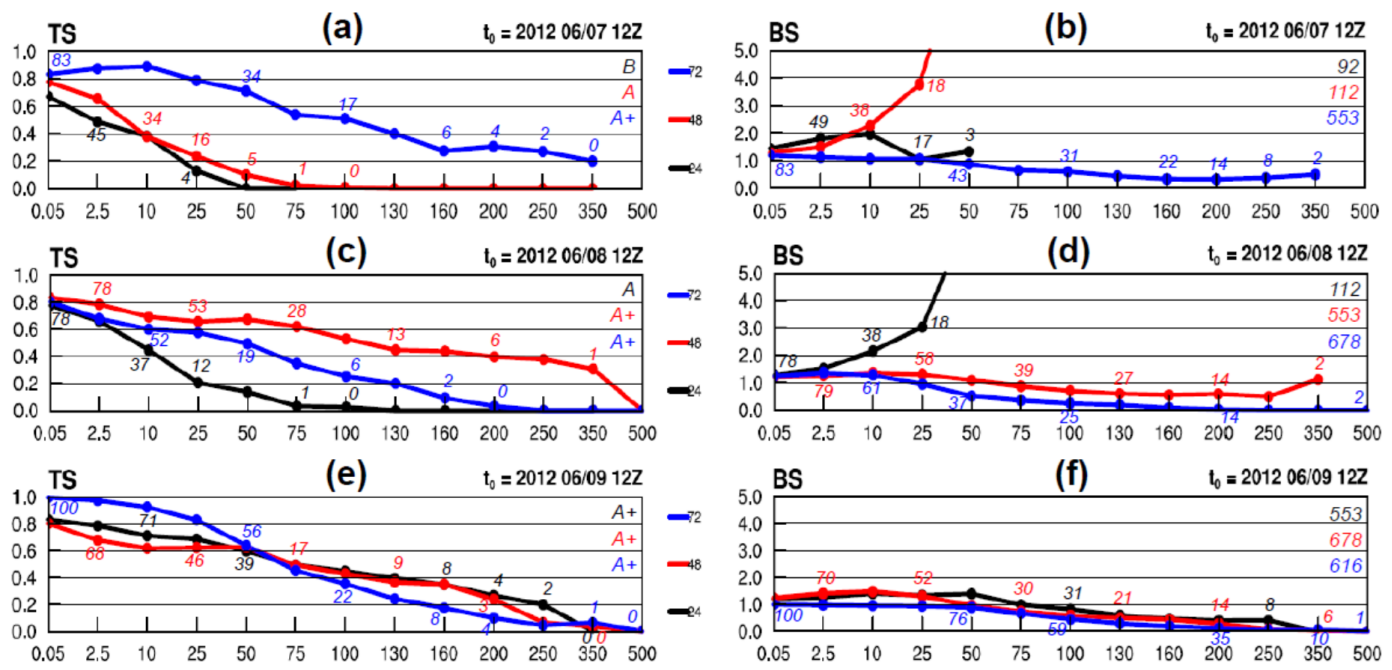

$$
\begin{aligned}
& -72 \\
& -48 \\
& -4
\end{aligned}
$$
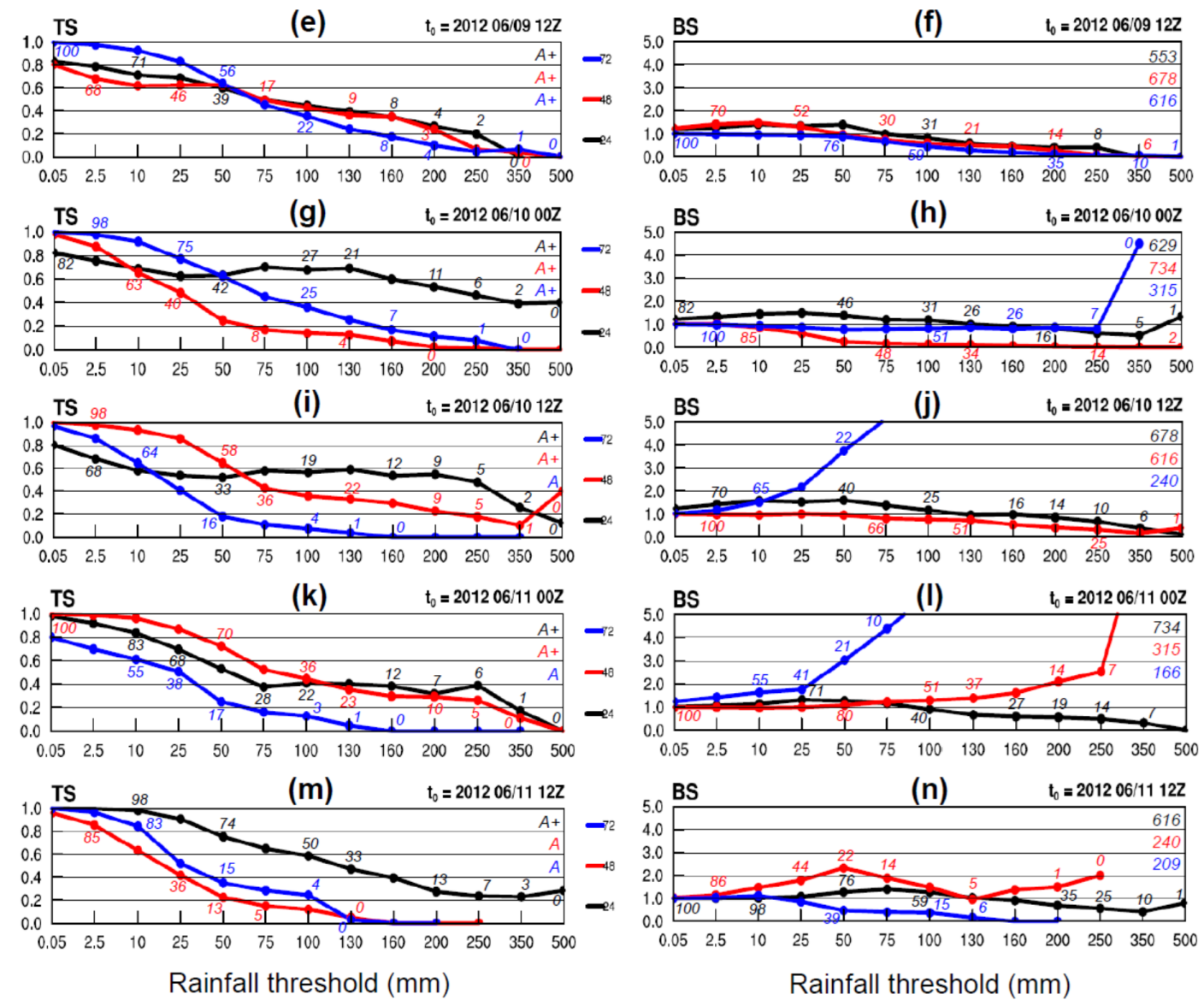

Figure 7. (a) TS and (b) BS of day - 1 (black), day - 2 (red), and day - 3 (blue) QPFs made at 12:00 UTC 7 June 2012 as a function of rainfall threshold $(\mathrm{mm}$; per $24 \mathrm{~h})$. The hit rate $(H / N$; $\%$; rounded to integer) at selected points and the classification group for each day are labeled in the left panel (for TS). The observed base rate $(O / N ; \%)$ and peak $24 \mathrm{~h}$ rainfall $(\mathrm{mm})$ are labeled in the right panel (for BS). (c, d) to $(\mathbf{m}, \mathbf{n})$ As in (a, b), except for the QPFs made at (c, d) 12:00 UTC 8 June, (e, f) 12:00 UTC 9 June, (g, h) 00:00 UTC and (i, j) 12:00 UTC 10 June, and (k, l) 00:00 UTC and (m, n) 12:00 UTC 11 June 2012, respectively.

Consistent with Fig. 4, an overprediction is more likely to happen for smaller events (A or below), across low thresholds below $50 \mathrm{~mm}$, and/or when the rain area becomes small. In Fig. 7, for example, $\mathrm{BS} \geq 2$ at high thresholds for the A+ group occurs only when $O / N$ approaches zero (Fig. 7h and $\mathrm{n}$ ), with the only exception in Fig. 71 on day 2. Overall, the model does not have a tendency to overpredict such a large event (cf. Fig. 6).
The forecasts on days 1-2 produced by the run starting at 12:00 UTC 10 June are compared with radar observations in Fig. 9. Together with Fig. 8, the radar panels cover the wettest 72 h (06:00 UTC 9-12 June) of the entire event. During day 1 (Fig. 9a-h), the scenario remains similar to Fig. 8, and the model again was able to capture the mountain rainfall. The convection moving in from the Taiwan Strait, however, was too active, and the rain along the western coast on 

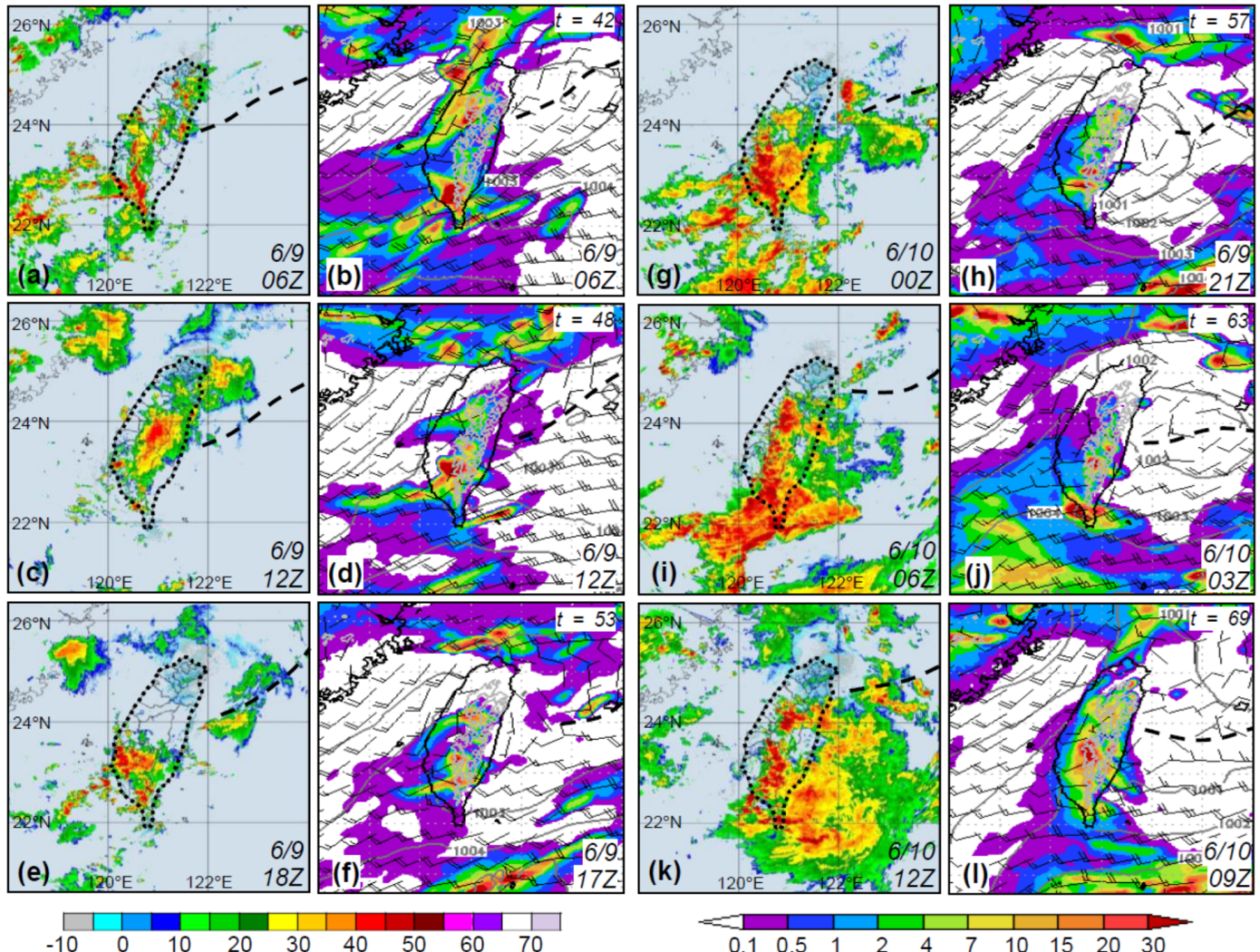

$\begin{array}{llllllllll}0.1 & 0.5 & 1 & 2 & 4 & 7 & 10 & 15 & 20 & 30\end{array}$

Figure 8. (a, c, e, g, i, k) Radar reflectivity composite (dBZ; scale at bottom left) in the Taiwan area (width roughly $600 \mathrm{~km}$ ) every $6 \mathrm{~h}$ from (a) 06:00 UTC 9 June to (k) 12:00 UTC 10 June 2012 (original plots provided by the CWB). (b, d, f, h, j, l) The CReSS forecast, starting from 12:00 UTC 7 June 2012, of sea-level pressure (hPa; every $1 \mathrm{hPa}$, over ocean only), surface wind (kn; barbs, at $10 \mathrm{~m}$ ), terrain height at 1 and $2 \mathrm{~km}$ (gray contours), and hourly rainfall ( $\mathrm{mm}$; color, scale at bottom right) valid at the time or within $3 \mathrm{~h}$ of the radar composite as labeled - in UTC (forecast time in h) in lower (upper) right corner - over the same area. The thick dashed lines mark the position of surface frontal or wind-shift line, based on NCEP gridded analyses for the observation (outline of Taiwan also highlighted).

day 1 was overpredicted with $\mathrm{BSs} \approx 1.2-1.6$ from 0.05 up to $100 \mathrm{~mm}$ (cf. Fig. 7j). Note that in Fig. 7, some overprediction across low thresholds can also exist for group A+ and lowers the TS, which otherwise can often exceed 0.8 at and below $25 \mathrm{~mm}$. In any case, the model's performance over the low thresholds is of secondary importance.

Since 12:00 UTC 11 June, the Mei-yu front gradually approached northern Taiwan, and its western section moved rapidly across the island after about 00:00 UTC 12 June (Fig. 9i-p). Studied by Wang et al. (2016b), the heavy rainfall in northern Taiwan (during 14:00-24:00 UTC) was caused by quasi-linear convection that developed south of the front (Fig. 9i, k, and m), along a convergence zone between the low-level flow blocked and deflected by Taiwan's topography and unblocked flow further to the northwest (but still prefrontal) in the environment (e.g., Li and Chen, 1998; Yeh and Chen, 2002; Chen et al., 2005; Wang et al., 2005). In the model forecast, with apparent errors in the position and moving speed of the front (Fig. 9i-p), it is highly challenging to produce a similar system at the correct location and time even when the overall scenario surrounding northern
Taiwan is reasonably predicted. In the simulation of Wang et al. (2016b), the rainbands cannot be fully captured even with a finer grid of $\Delta x=1.5 \mathrm{~km}$ and the NCEP final analyses as IC/BCs. Likely mainly linked to the IC/BCs, the position error in the front in this case is still a major error source for the rainfall associated with the front. Thus, although the model did indicate a real possibility of heavy rainfall in northern Taiwan in Fig. 9, the high TS of 0.4 at $500 \mathrm{~mm}$ on day 2 (Fig. 7i) came from the mountains, where the rainfall prediction is clearly more accurate (cf. Fig. 6a and c, column 7), consistent with Walser and Schär (2004). Of course, the day -1 QPF with $t_{0}=12: 00$ UTC 11 June performed better in northern Taiwan than our example, but the goal here is to illustrate the relatively high accuracy to predict heavy rainfall phase-locked to the topography versus the low accuracy for rainfall produced by transient systems over low-lying plains.

The above example, together with other cases including those on 20 May 2013 and 20-21 May 2014, (cf. Table 3, not shown), suggests a lower accuracy and a more challenging task for model QPFs to capture the heavy rainfall pro- 

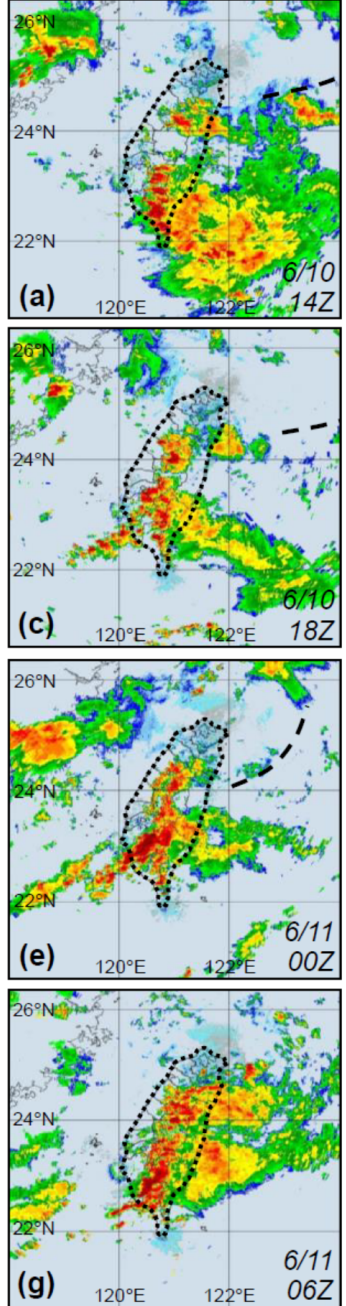

$120^{\circ} \mathrm{E}$

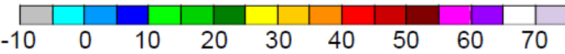

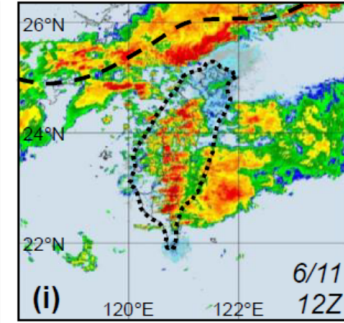
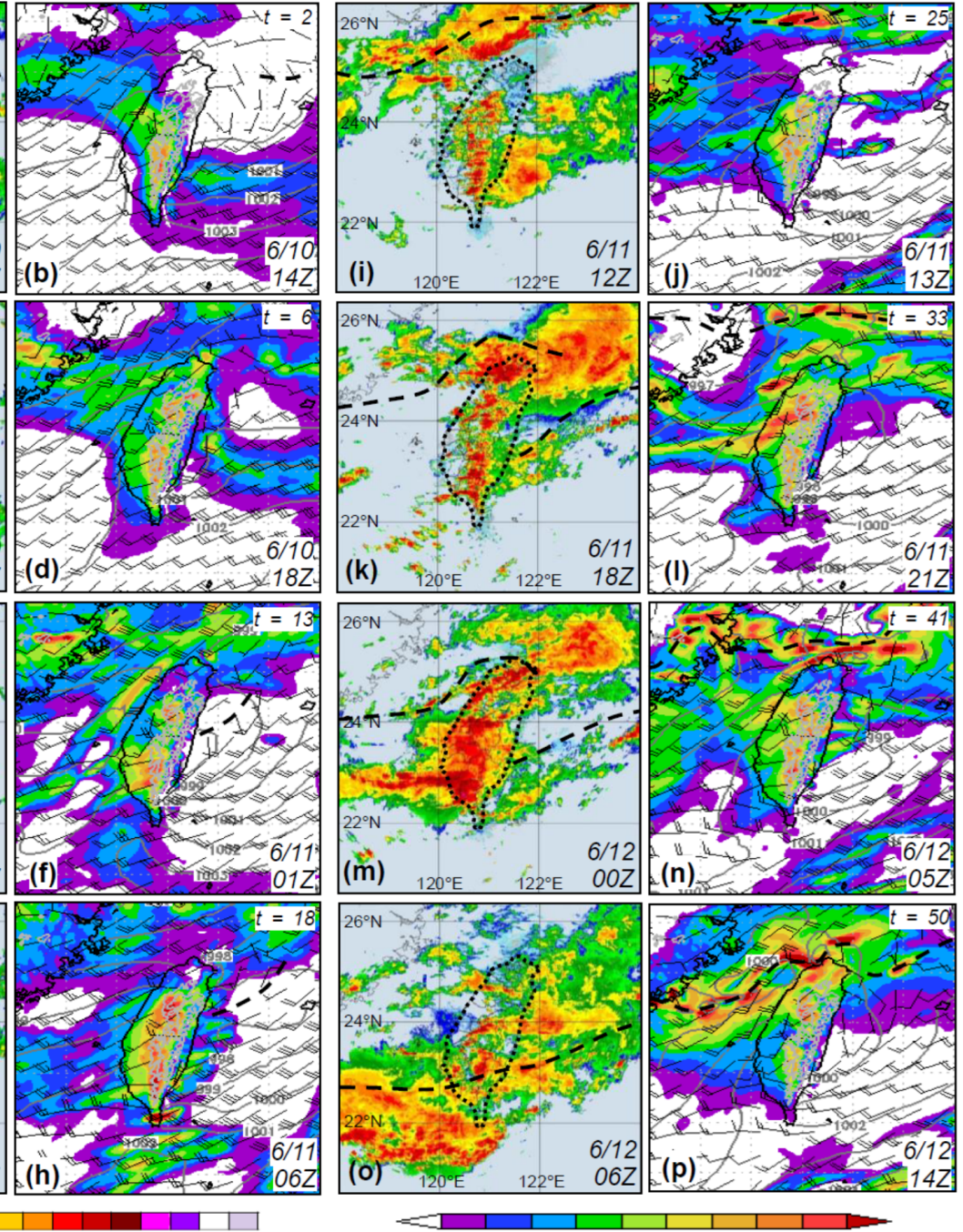

$\begin{array}{lllllllllll}0.1 & 0.5 & 1 & 2 & 4 & 7 & 10 & 15 & 20 & 30\end{array}$

Figure 9. As in Fig. 8, but showing (a, c, e, $\mathbf{g}, \mathbf{i}, \mathbf{k}, \mathbf{m}, \mathbf{o})$ radar reflectivity composite (dBZ) at (a) 14:00 UTC 10 June and every $6 \mathrm{~h}$ from (c) 18:00 UTC 10 June to (o) 06:00 UTC 12 June 2012 and (b, d, f, h, j, l, n, p) the CReSS forecast, starting from 12:00 UTC 10 June 2012, of sea-level pressure $(\mathrm{hPa})$, surface wind $(\mathrm{kn})$, and hourly rainfall $(\mathrm{mm})$ valid at the time or within up to $8 \mathrm{~h}$ (towards the end) of the radar composite (as labeled).

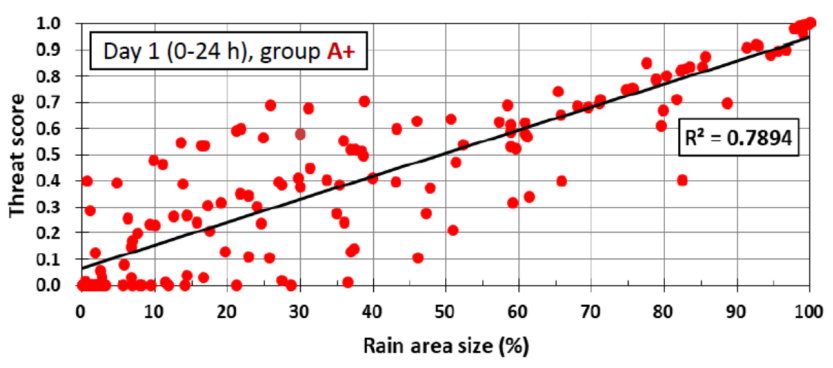

Figure 10. Scatterplot of TS versus observed rain area size (\%) from day -1 QPFs for group A+ from $0 \%$ to $100 \%$ (from high to low rainfall threshold). The squared correlation coefficient $\left(R^{2}\right)$ is given. duced by transient systems often in close association with the Mei-yu front compared to topographic rainfall in Taiwan. Even though the overall scenario is reasonably and realistically predicted (cf. Figs. 8 and 9), some position errors on the Mei-yu front are almost inevitable, and the intrinsic predictability can limit the accuracy of the QPF (e.g., Hochman et al., 2021). Also, for such rainfall caused by transient systems, categorical statistics are known to be less effective in verifying model QPFs (e.g., Davis et al., 2006; Wernli et al., 2008; Gilleland et al., 2010). However, for the quasistationary, phase-locked rainfall over the topography in the majority of large events (in both Mei-yu and typhoon seasons; e.g., Chang et al., 1993; Cheung et al., 2008) in Taiwan, they are still valid and useful, as shown herein. As model resolution increases, both the topography and deep convection 

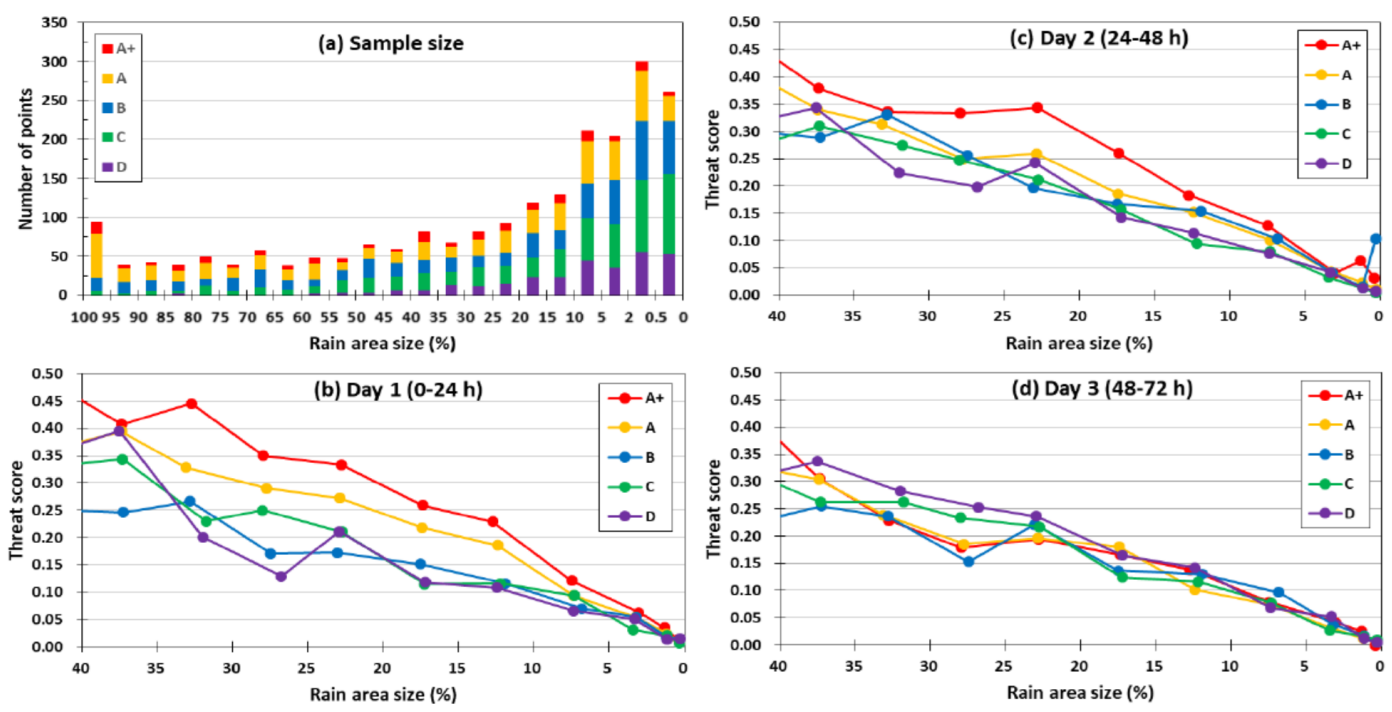

Figure 11. (a) The distribution of data points in the bins of observed rain area size (\%; every $5 \%$ from $100 \%$ to $5 \%$, then $2 \%-5 \%$, $0.5 \%-$ $2 \%$, and $<0.5 \%$; same for days 1-3) among groups A+ and A to D. (b-d) The TS of $24 \mathrm{~h}$ QPFs for (b) day 1 to (d) day 3, respectively, as a function of observed rain area size between $40 \%$ and $0 \%$.

can be better resolved, leading to improved QPFs over the terrain.

\section{Dependency of categorical scores on event size}

In Sect. 3, a positive dependency in categorical measures by CReSS, including TS, POD, and FAR, on rainfall amount is shown for the Mei-yu regime in Taiwan, as predicted. Also discussed in $\mathrm{W} 15$, this property arises mainly due to the positive correlation between the scores and rain area sizes, as illustrated in Fig. 10, with a correlation coefficient $r=0.89$ for the Mei-yu regime. However, to explore whether the model is indeed more skillful in predicting larger rainfall events, further analysis with the factor of rain area size removed is needed. Different from W15, our approach here is described below.

For each segment, the statistics $(H, M, \mathrm{FA}$, and $\mathrm{CN})$ at 13 fixed thresholds of $0.05-500 \mathrm{~mm}$, each occurring at a certain $O / N$ (if the threshold is equal to or less than the observed peak amount), are known. The observed base rate $(0 \%-100 \%)$ is divided into bins every $5 \%$ except at $0 \%-$ $5 \%$, where it is subdivided into $0 \%-0.5 \%, 0.5 \%-2 \%$, and $2 \%-5 \%$ to give more comparable sample size. For each group (A+ or A-D), the statistics are then summed for each bin regardless of their rainfall threshold. Thus, those in the same bin come from rain areas with similar sizes. In Fig. 11a, the distribution of total counts of thresholds across $O / N$ is plotted, and the larger events toward $\mathrm{A}+$ are more capable of producing rain areas larger in size (say, $\geq 60 \%$ of Taiwan). Also, the counts remain mostly around 50 for $O / N \geq 40 \%$, then rise to $200-300$ with $O / N \leq 10 \%$.
Due to fewer samples at larger $O / N$ values, the TSs for different groups (from a single $2 \times 2$ table for each bin) are presented only for $O / N \leq 40 \%$ in Fig. 11b-d. While the scores for B-D are roughly the same, the TSs for A are clearly higher compared to those on day 1 , and those for A+ are again higher compared to $\mathrm{A}$ on days 1 and 2 over most parts of this range, sometimes by $0.05-0.1$, when the factor of rain area size is removed (Fig. $11 \mathrm{~b}$ and c). On day 3 (Fig. 11d), however, the TSs for larger events $(\mathrm{A}+$ and $\mathrm{A})$ show no particular advantage. Therefore, similar to typhoons in W15, the $2.5 \mathrm{~km} \mathrm{CReSS}$ is more skillful in predicting the larger Mei-yu events in Taiwan within $2 \mathrm{~d}$ over the heavyrainfall area (again, mainly over the mountains).

The higher TSs and better skill for large events at $O / N$ within $40 \%$ (Fig. 11) are most likely linked to the more favorable conditions at synoptic to meso- $\alpha$ scale, which the model is capable of capturing with higher accuracy (e.g., Walser and Schär, 2004). To briefly elaborate on this aspect, seven items on the checklist used by CWB forecasters in the Mei-yu season as a guidance to issue heavy-rainfall warning (e.g., Wang et al., 2012a) are selected, and their occurrence frequency, judged using surface weather maps and NCEP gridded analyses at the starting time of each $24 \mathrm{~h}$ period, is compiled for different groups. These items include (1) presence of surface Mei-yu front inside $20-28^{\circ} \mathrm{N}, 118-124^{\circ} \mathrm{E}$; (2) Taipei (cf. Fig. 3) within $200 \mathrm{~km}$ south and $100 \mathrm{~km}$ north of the front; (3) Kaohsiung (cf. Fig. 3) within $200 \mathrm{~km}$ south of the front; (4) presence of a low-level jet (LLJ) inside $18-26^{\circ} \mathrm{N}, 115-125^{\circ} \mathrm{E}$ at 850 or $700 \mathrm{hPa}$; (5) presence of mesolow near Taiwan; (6) Taiwan inside a low-pressure zone; and (7) the mean sea-level pressure in Taiwan below $1005 \mathrm{hPa}$. The results (Fig. 12) indicate that among the seven 


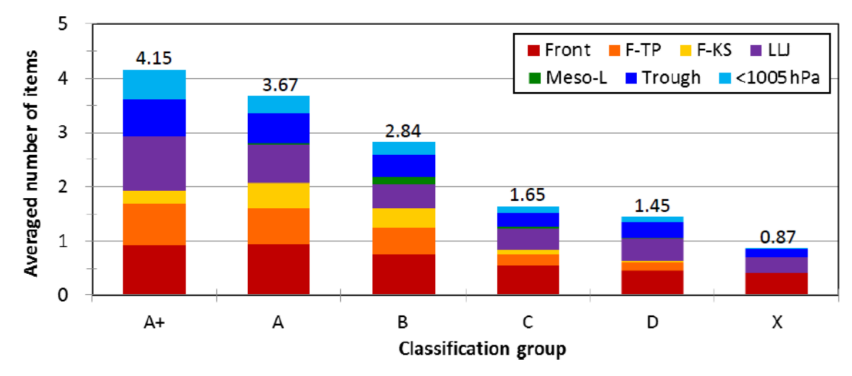

Figure 12. The average number of items met, among the seven items on the checklist, at the starting time of $24 \mathrm{~h}$ segments for different classification groups (from $\mathrm{A}+, \mathrm{A}$ to $\mathrm{D}$, and $\mathrm{X}$ ), with the value labeled on top. Following the order (bottom to top), the seven items are presence of surface Mei-yu front (front), front near Taipei (F-TP), front near Kaohsiung (F-KS), presence of LLJ, mesolow (meso-L), Taiwan inside a low-pressure zone (trough), and the mean sea-level pressure lower than $1005 \mathrm{hPa}(<1005 \mathrm{hPa})$, respectively. The items are plotted in different colors (see insert) to show their proportion.

items, an average of 4.15 items are met in group $\mathrm{A}+$, and this figure gradually declines toward smaller groups, from 3.67 in A, 2.84 in B, and finally to only 0.87 in X. Thus, as expected, the synoptic- and meso- $\alpha$-scale conditions tend to be more favorable in larger events, which in general also correspond to higher TS values (Figs. 3 and 11) in combination with the orographic forcing in Taiwan.

\section{Summary and concluding remarks}

In this study, the QPFs at the ranges of $1-3 \mathrm{~d}$ by the $2.5 \mathrm{~km}$ CReSS during three Mei-yu seasons (May-June) in Taiwan of 2012-2014 are evaluated using categorical statistics, with an emphasis on heavy to extreme rainfall events (100$500 \mathrm{~mm}$ per $24 \mathrm{~h}$ ). Overall, the TSs of day -1 QPFs for all events (no classification) at thresholds of 100, 250, and $500 \mathrm{~mm}$ are $0.18,0.15$, and 0.09 , respectively. Compared to previous and contemporary results from models at lower resolutions for the Mei-yu season in Taiwan, where the TSs are no higher than 0.1 at $100 \mathrm{~mm}$ and 0.02 at $250 \mathrm{~mm}$ and beyond (Sect. 1; e.g., Hsu et al., 2014; Li and Hong, 2014; Su et al., 2016; Huang et al., 2016), the results herein show considerable improvements by the $2.5 \mathrm{~km}$ CReSS, especially over the heavy-rainfall thresholds.

Moreover, the ability to represent the extreme and top events (group $\mathrm{A}+$ ) in terms of the TS is much greater when a proper classification based on observed rain area size (i.e., event magnitude) is used. For the top $4 \%$ and most hazardous Mei-yu events, the day -1 QPFs have TSs of 0.34, 0.24, and 0.16, respectively. The QPFs for larger events also exhibit higher POD, lower FAR, and higher TS than smaller ones across nearly all thresholds at all ranges of days 1-3. Thus, the positive dependency of categorical scores on the overall rainfall amount also exists in the Mei-yu regime in Taiwan, as predicted by W15 (and Wang, 2016).

For a selected case study, the improvement by the $2.5 \mathrm{~km}$ CReSS in Taiwan is shown to lie in an improved ability to capture the phase-locked topographic rainfall at its correct location in larger events at heavy-rainfall thresholds. For rainfall in the mountains, the QPFs tend to be more accurate as the CRM can better resolve both the terrain and convection (e.g., Walser and Schär, 2004; Roberts and Lean, 2007). In contrast, the accuracy of QPFs for concentrated rainfall caused by transient systems (such as frontal squall lines) could not be demonstrated, probably due to the difficulty of predicting at the correct time and location owing to nonlinearity, even though a realistic scenario is produced. Overall, the high-resolution models showed a higher QPF accuracy in categorical statistics for extreme events than coarserresolution models over the geographic region of Taiwan, as demonstrated here (and in W15). Such QPFs can be helpful for hazard preparation and mitigation.

Code and data availability. The model used in this study, the Cloud-Resloving Storm Simulator, is available for download (code and user's guide) at http://www.rain.hyarc.nagoya-u.ac.jp/ tsuboki/ cress_html/index_cress_eng.html (CReSS, 2021).

Author contributions. CCW designed the experiments, and PYC carried them out. CSC operated the real-time model forecasting, and KT created the model code. SYH helped with some figures, and GCL provided some CWB results. CCW prepared the manuscript with contributions from all co-authors.

Competing interests. The contact author has declared that neither they nor their co-authors have any competing interests.

Disclaimer. Publisher's note: Copernicus Publications remains neutral with regard to jurisdictional claims in published maps and institutional affiliations.

Acknowledgements. Constructive comments and suggestions from two anonymous reviewers and George Tai-Jen Chen of the National Taiwan University are appreciated. The first author, Chung-Chieh Wang, wishes to thank assistants Yi-Wen Wang, Tzu-Chun Lin, and $\mathrm{Ka}-\mathrm{Yu}$ Chen for their help in this study. The CWB is acknowledged for providing the observational data, the radar plots, and the QPF verification results in Fig. 2. The National Center for Highperformance Computing (NCHC) and the Taiwan Typhoon and Flood Research Institute (TTFRI) provided the computational resources. This study is jointly supported by the Ministry of Science and Technology of Taiwan under Grants MOST-103-2625-M-003001-MY2, MOST-105-2111-M-003-003-MY3, MOST-108-2111M-003-005-MY2, MOST-110-2111-M-003-004, and MOST-1102625-M-003-001. 
Financial support. This research has been supported by the Ministry of Science and Technology of Taiwan (grant nos. MOST-1082111-M-003-005-MY2, MOST-109-2625-M-003-001, MOST-1102111-M-003-004, and MOST-110-2625-M-003-001).

Review statement. This paper was edited by Joaquim G. Pinto and reviewed by two anonymous referees.

\section{References}

Barnes, L. R., Schultz, D. M., Gruntfest, E. C., Hayden, M. H., and Benight, C. C.: Corrigendum: False alarm rate or false alarm ratio?, Weather Forecast., 24, 1452-1454, https://doi.org/10.1175/2009WAF2222300.1, 2009.

Bryan, G. H., Wyngaard, J. C., and Fritsch, J. M.: Resolution requirements for the simulation of deep moist convection, Mon. Weather Rev., 131, 2394-2416, https://doi.org/10.1175/15200493(2003)131<2394:RRFTSO>2.0.CO;2, 2003.

Chang, C.-P., Yeh, T.-C., and Chen, J.-M.: Effects of terrain on the surface structure of typhoons over Taiwan, Mon. Weather Rev., 121, 734-752, https://doi.org/10.1175/15200493(1993)121<0734:EOTOTS>2.0.CO;2, 1993.

Chang, C.-P., Yang, Y.-T., and Kuo, H.-C.: Large increasing trend of tropical cyclone rainfall in Taiwan and the roles of terrain, J. Climate, 26, 4138-4147, https://doi.org/10.1175/JCLI-D-1200463.1, 2013.

Chen, C.-S. and Chen, Y.-L.: The rainfall characteristics of Taiwan, Mon. Weather Rev., 131, 1324-1341, 2003.

Chen, G. T.-J., Wang, C.-C., and Lin, D. T.-W.: Characteristics of low-level jets over northern Taiwan in Mei-yu season and their relationship to heavy rain events, Mon. Weather Rev., 133, 2043, https://doi.org/10.1175/MWR-2813.1, 2005.

Chen, T.-C., Yen, M.-C., Hsieh, J.-C., and Arritt, R. W.: Diurnal and seasonal variations of the rainfall measured by the Automatic Rainfall and Meteorological Telemetry System in Taiwan, B. Am. Meteorol. Soc., $\quad 80, \quad 2299-2312$, https://doi.org/10.1175/15200477(1999)080<2299:DASVOT>2.0.CO;2, 1999.

Cheung, K. K. W., Huang, L.-R., and Lee, C.-S.: Characteristics of rainfall during tropical cyclone periods in Taiwan, Nat. Hazards Earth Syst. Sci., 8, 1463-1474, https://doi.org/10.5194/nhess-81463-2008, 2008.

Chi, S.-S.: The Mei-Yu in Taiwan, SFRDEST E-06-MT-03-4, Chung-Shin Engineering Technology Research and Development Foundation, Taipei, Taiwan, 65 pp., 2006.

Chien, F.-C. and Jou, B. J.-D.: MM5 ensemble mean precipitation in the Taiwan area for three early summer convective (Mei-Yu) seasons, Weather Forecast., 19, 735-750, 2004.

Chien, F.-C., Kuo, Y.-H., and Yang, M.-J.: Precipitation forecast of MM5 in the Taiwan area during the 1998 Mei-yu season, Weather Forecast., 17, 739-754, https://doi.org/10.1175/15200434(2002)017<0739:PFOMIT>2.0.CO;2, 2002.

Chien, F.-C., Liu, Y.-C., and Jou, B. J.-D.: MM5 ensemble mean forecasts in the Taiwan area for the 2003 Mei-yu season, Weather Forecast., 21, 1006-1023, https://doi.org/10.1175/WAF960.1, 2006.
Clark, A. J., Gallus Jr., W. A., and Chen, T.-C.: Comparison of the diurnal precipitation cycle in convection-resolving and nonconvection-resolving mesoscale models, Mon. Weather Rev., 135, 3456-3473, https://doi.org/10.1175/MWR3467.1, 2007.

Clark, A. J., Kain, J. S., Stensrud, D. J., Xue, M., Kong, F., Coniglio, M. C., Thomas, K. W., Wang, Y., Brewster, K., Gao, J., Wang, X., Weiss, S. J., and Du, J.: Probabilistic precipitation forecast skill as a function of ensemble size and spatial scale in a convection-allowing ensemble, Mon. Weather Rev., 139, 14101418, https://doi.org/10.1175/2010MWR3624.1, 2011.

Cotton, W. R., Tripoli, G. J., Rauber, R. M., and Mulvihill, E. A.: Numerical simulation of the effects of varying ice crystal nucleation rates and aggregation processes on orographic snowfall, J. Appl. Meteorol. Clim., 25, 1658-1680, https://doi.org/10.1175/15200450(1986)025<1658:NSOTEO>2.0.CO;2, 1986.

CReSS: CReSS home page, available at: http://www.rain.hyarc. nagoya-u.ac.jp/ tsuboki/cress_html/index_cress_eng.html, last access: 28 December 2021.

Cuo, L., Pagano, T. C., and Wang, Q. J.: A review of quantitative precipitation forecasts and their use in short- to mediumrange streamflow forecasting, J. Hydormeteorol., 12, 713-728, https://doi.org/10.1175/2011JHM1347.1, 2011.

Davis, C., Brown, B., and Bullock, R.: Object-based verification of precipitation forecasts. Part I: Methodology and application to mesoscale rain areas, Mon. Weather Rev., 134, 1772-1784, https://doi.org/10.1175/MWR3145.1, 2006.

Deardorff, J. W.: Stratocumulus-capped mixed layers derived from a three-dimensional model, Bound.-Lay. Meteorol., 18, 495-527, 1980.

Done, J., Davis, C. A., and Weisman, M.: The next generation of NWP: explicit forecasts of convection using the weather research and forecasting (WRF) model, Atmos. Sci. Lett., 5, 110-117, 2004.

Ebert, E. E.: Ability of a poor man's ensemble to predict the probability and distribution of precipitation, Mon. Weather Rev., 129, 2461-2480, https://doi.org/10.1175/15200493(2001)129<2461:AOAPMS>2.0.CO;2, 2001.

Ebert, E. E. and McBride, J. L.: Verification of precipitation in weather systems: Determination of systematic errors, J. Hydrol., 239, 179-202, https://doi.org/10.1016/S0022-1694(00)00343-7, 2000.

Ebert, E. E., Damrath, U., Wergen, W., and Baldwin, M. E.: The WGNE assessment of short-term quantitative precipitation forecasts (QPFs) from operational numerical weather prediction models, B. Am. Meteorol. Soc., 84, 481-492, https://doi.org/10.1175/BAMS-84-4-481, 2003.

Fang, X. and Kuo, Y.-H.: Improving ensemble-based quantitative precipitation forecasts for topography-enhanced typhoon heavy rainfall over Taiwan with a modified probabilitymatching technique, Mon. Weather Rev., 141, 3908-3932, https://doi.org/10.1175/MWR-D-13-00012.1, 2013.

Fritsch, J. M. and Carbone, R. E.: Improving quantitative precipitation forecasts in the warm season. A USWRP research and development strategy, B. Am. Meteorol. Soc., 85, 955-965, https://doi.org/10.1175/BAMS-85-7-955, 2004.

Gilleland, E., Ahijevych, D. A., Brown, B. G., and Ebert, E. E.: Verifying forecasts spatially, B. Am. Meteorol. Soc., 91, 13651373, https://doi.org/10.1175/2010BAMS2819.1, 2010. 
Golding, B. W.: Quantitative precipitation forecasting in the UK, J. Hydrol., 239, 286-305, https://doi.org/10.1016/S00221694(00)00354-1, 2000.

Hochman, A., Scher, S., Quinting, J., Pinto, J. G., and Messori, G.: A new view of heat wave dynamics and predictability over the eastern Mediterranean, Earth Syst. Dynam., 12, 133-149, https://doi.org/10.5194/esd-12-133-2021, 2021.

Hong, J.-S., Fong, C.-T., Hsiao, L.-F., Yu, Y.-C., and Tseng, C.-Y.: Ensemble typhoon quantitative precipitation forecasts model in Taiwan, Weather Forecast., 30, 217-237, https://doi.org/10.1175/WAF-D-14-00037.1, 2015.

Hsu, J. C.-S., Wang, C.-J., Chen, P.-Y., Chang, T.-H., and Fong, C.-T.: Verification of quantitative precipitation forecasts by the CWB WRF and ECMWF on $0.125^{\circ}$ grid, in: Proceedings of 2014 Conference on Weather Analysis and Forecasting, 1618 September 2014, Central Weather Bureau, Taipei, Taiwan, A2-24, 2014.

Huang, T.-S., Yeh, S.-H., Leu, G.-C., and Hong, J.-S.: A synthesis and comparison of QPF verifications at the CWB and major NWP guidance, in: Proceedings of 2015 Conference on Weather Analysis and Forecasting, 15-17 September 2015, Central Weather Bureau, Taipei, Taiwan, A7-11, 2015.

Huang, T.-S., Yeh, S.-H., Leu, G.-C., and Hong, J.-S.: Postprocessing of ensemble rainfall forecasts - Ensemble mean, probability matched mean and exceeding probability, Atmos. Sci., 44, 173196, 2016.

Ikawa, M. and Saito, K: Description of a non-hydrostatic model developed at the Forecast Research Department of the MRI, Technical Report 28, Meteorological Research Institute, Tsukuba, Ibaraki, Japan, 245 pp., 1991.

Jou, B. J.-D., Lee, W.-C., and Johnson, R. H.: An overview of SoWMEX/TiMREX, in: The Global Monsoon System: Research and Forecast, 2nd Edn., edited by: Chang, C.-P., Ding, Y., Lau, N.-C., Johnson, R. H., Wang, B., and Yasunari, T., World Scientific, Toh Tuck Link, Singapore, 303-318, https://doi.org/10.1142/9789814343411_0018, 2011.

Kalnay, E., Kanamitsu, M., and Baker, W. E.: Global numerical weather prediction at the National Meteorological Center, B. Am. Meteorol. Soc., 71, 1410-1428, 1990.

Kanamitsu, M.: Description of the NMC global data assimilation and forecast system, Weather Forecast., $\quad 4, \quad 335-342, \quad$ https://doi.org/10.1175/15200434(1989)004<0335:DOTNGD>2.0.CO;2, 1989.

Kleist, D. T., Parrish, D. F., Derber, J. C., Treadon, R., Wu, W. S., and Lord, S.: Introduction of the GSI into the NCEP global data assimilation system, Weather Forecast., 24, 1691-1705, https://doi.org/10.1175/2009WAF2222201.1, 2009.

Kondo, J.: Heat balance of the China Sea during the air mass transformation experiment, J. Meteorol. Soc. Jpn., 54, 382-398, https://doi.org/10.2151/jmsj1965.54.6_382, 1976.

Kuo, Y.-H. and Chen, G. T.-J.: The Taiwan Area Mesoscale Experiment (TAMEX): An overview, B. Am. Meteorol. Soc., 71, 488-503, https://doi.org/10.1175/15200477(1990)071<0488:TTAMEA>2.0.CO;2, 1990.

Li, C.-H. and Hong, J.-S.: Study on the application and analysis of regional ensemble quantitative precipitation forecasts, in: Proceedings of 2014 Conference on Weather Analysis and Forecasting, 16-18 September 2014, Central Weather Bureau, Taipei, Taiwan, A2-19, 2014.
Li, J. and Chen, Y.-L.: Barrier jets during TAMEX, Mon. Weather Rev., 126, 959-971, https://doi.org/10.1175/15200493(1998)126<0959:BJDT>2.0.CO;2, 1998.

Lin, Y.-L., Farley, R. D., and Orville, H. D.: Bulk parameterization of the snow field in a cloud model, J. Appl. Meteorol. Clim., 22, 1065-1092, https://doi.org/10.1175/15200450(1983)022<1065:BPOTSF>2.0.CO;2, 1983.

Louis, J. F., Tiedtke, M., and Geleyn, J. F.: A short history of the operational PBL parameterization at ECMWF, in: Proceedings of Workshop on Planetary Boundary Layer Parameterization, 2527 November 1981, Shinfield Park, Reading, UK, 59-79, 1982.

Moorthi, S., Pan, H. L., and Caplan, P.: Changes to the 2001 NCEP operational MRF/AVN global analysis/forecast system, NWS Technical Procedures Bulletin 484, Office of Meteorology, National Weather Service, Silver Spring, Maryland, USA, 2001.

Murakami, M.: Numerical modeling of dynamical and microphysical evolution of an isolated convective cloud - The 19 July 1981 CCOPE cloud, J. Meteorol. Soc. Jpn., 68, 107-128, https://doi.org/10.2151/jmsj1965.68.2_107, 1990.

Murakami, M., Clark, T. L., and Hall, W. D.: Numerical simulations of convective snow clouds over the Sea of Japan: Twodimensional simulation of mixed layer development and convective snow cloud formation, J. Meteorol. Soc. Jpn., 72, 43-62, https://doi.org/10.2151/jmsj1965.72.1_43, 1994.

Paul, S., Wang, C.-C., Chien, F.-C., and Lee, D.-I.: An evaluation of the WRF Mei-yu rainfall forecasts in Taiwan, 2008-2010: differences in elevation and sub-regions, Meteorol. Appl., 25, 269282, https://doi.org/10.1002/met.1689, 2018.

Roberts, N. M. and Lean, H. W.: Scale-selective verification of rainfall accumulations from high-resolution forecasts of convective events, Mon. Weather Rev., 136, 78-97, https://doi.org/10.1175/2007MWR2123.1, 2007.

Roebber, P. J.: Visualizing multiple measures of forecast quality, Weather Forecast., 24, 601-608, https://doi.org/10.1175/2008WAF2222159.1, 2009.

Schaefer, J. T.: The critical success index as an indicator of warning skill, Weather Forecast., 5, 570-575, https://doi.org/10.1175/15200434(1990)005<0570:TCSIAA>2.0.CO;2, 1990.

Segami, A., Kurihara, K., Nakamura, H., Ueno, M., Takano, I., and Tatsumi, Y.: Operational mesoscale weather prediction with Japan Spectral Model, J. Meteorol. Soc. Jpn., 67, 907-924, https://doi.org/10.2151/jmsj1965.67.5_907, 1989.

Skamarock, W. C., Klemp, J. B., Dudhia, J., Gill, D. O., Barker, D. M., Wang, W., and Powers, J. G.: A description of the advanced research WRF version 2, National Center for Atmospheric Reasearch, Boulder, Colorado, USA, 88 pp., https://doi.org/10.5065/D6DZ069T, 2005.

Su, Y.-J., Hong, J.-S., and Li, C.-H.: The characteristics of the probability matched mean QPF for 2014 Meiyu season, Atmos. Sci., 44, 113-134, 2016.

Tsuboki, K. and Sakakibara, A.: Large-scale parallel computing of cloud resolving storm simulator, in: High Performance Computing, edited by: Zima, H. P., Joe, K., Sato, M., Seo, Y., and Shimasaki, M., Springer, Berlin, Heidelberg, Germany, 243-259, https://doi.org/10.1007/3-540-47847-7_21, 2002.

Tsuboki, K. and Sakakibara, A.: Numerical Prediction of HighImpact Weather Systems: The Textbook for the Seventeenth IHP Training Course in 2007, Hydrospheric Atmospheric Research 
Center, Nagoya University, Nagoya, Japan, and UNESCO, Paris, France, 273 pp., 2007.

Walser, A. and Schär, C.: Convection-resolving precipitation forecasting and its predictability in Alpine river catchments, J. Hydrol., 288, 57-73, https://doi.org/10.1016/j.jhydrol.2003.11.035, 2004.

Wang, C.-C.: On the calculation and correction of equitable threat score for model quantitative precipitation forecasts for small verification areas: The example of Taiwan, Weather Forecast., 29, 788-798, https://doi.org/10.1175/WAF-D-13-00087.1, 2014.

Wang, C.-C.: The more rain, the better the model performs - The dependency of quantitative precipitation forecast skill on rainfall amount for typhoons in Taiwan, Mon. Weather Rev., 143, 17231748, https://doi.org/10.1175/MWR-D-14-00137.1, 2015.

Wang, C.-C.: News and notes, Paper of notes: The more rain from typhoons, the better the models perform, B. Am. Meteorol. Soc., 97, 16-17, https://doi.org/10.1175/BAMS_971_11-18_Nowcast, 2016.

Wang, C.-C., Chen, G. T.-J., Chen, T.-C., and Tsuboki, K.: A numerical study on the effects of Taiwan topography on a convective line during the mei-yu season, Mon. Weather Rev., 133, 32173242, https://doi.org/10.1175/MWR3028.1, 2005.

Wang, C.-C., Chen, G. T.-J., and Huang, S.-Y.: Remote trigger of deep convection by cold outflow over the Taiwan Strait in the Mei-yu season: A modeling study of the 8 June 2007 Case, Mon. Weather Rev., 139, 2854-2875, https://doi.org/10.1175/2011MWR3613.1, 2011.

Wang, C.-C., Kung, C.-Y., Lee, C.-S., and Chen, G. T.-J.: Development and evaluation of Mei-yu season quantitative precipitation forecast in Taiwan river basins based on a conceptual climatology model, Weather Forecast., 27, 586-607, https://doi.org/10.1175/WAF-D-11-00098.1, 2012a.

Wang, C.-C., Kuo, H.-C., Chen, Y.-H., Huang, H.-L., Chung, C.-H., and Tsuboki, K.: Effects of asymmetric latent heating on typhoon movement crossing Taiwan: The case of Morakot (2009) with extreme rainfall, J. Atmos. Sci., 69, 31723196, https://doi.org/10.1175/JAS-D-11-0346.1, 2012 b.

Wang, C.-C., Chen, Y.-H., Kuo, H.-C., and Huang, S.-Y.: Sensitivity of typhoon track to asymmetric latent heating/rainfall induced by Taiwan topography: A numerical study of Typhoon Fanapi (2010), J. Geophys. Res.-Atmos., 118, 3292-3308, https://doi.org/10.1002/jgrd.50351, 2013a.
Wang, C.-C., Kuo, H.-C., Yeh, T.-C., Chung, C.-H., Chen, Y.-H., Huang, S.-Y., Wang, Y.-W., and Liu, C.-H.: Highresolution quantitative precipitation forecasts and simulations by the Cloud-Resolving Storm Simulator (CReSS) for Typhoon Morakot (2009), J. Hydrol., 506, 26-41, https://doi.org/10.1016/j.jhydrol.2013.02.018, 2013b.

Wang, C.-C., Huang, S.-Y., Chen, S.-H., Chang, C.-S., and Tsuboki, K.: Cloud-resolving typhoon rainfall ensemble forecasts for Taiwan with large domain and extended range through time-lagged approach, Weather Forecast., 31, 151-172, https://doi.org/10.1175/WAF-D-15-0045.1, 2016a.

Wang, C.-C., Chiou, B.-K., Chen, G. T.-J., Kuo, H.-C., and Liu, C.-H.: A numerical study of back-building process in a quasistationary rainband with extreme rainfall over northern Taiwan during 11-12 June 2012, Atmos. Chem. Phys., 16, 12359-12382, https://doi.org/10.5194/acp-16-12359-2016, 2016 b.

Wang, C.-C., Paul, S., Chien, F.-C., Lee, D.-I., and Chuang, P.-Y.: An evaluation of WRF rainfall forecasts in Taiwan during three mei-yu seasons of 2008-2010, Weather Forecast., 32, 13291351, https://doi.org/10.1175/WAF-D-16-0190.1, 2017.

Wernli, H., Paulat, M., Hagen, M., and Frei, C.: SAL - A novel quality measure for the verification of quantitative precipitation forecasts, Mon. Weather Rev., 136, 4470-4487, https://doi.org/10.1175/2008MWR2415.1, 2008.

Wilks, D. S.: Statistical methods in the atmospheric sciences, 3rd Edn., Academic Press, San Diego, California, USA, 2011.

Wu, C.-C. and Kuo, Y.-H.: Typhoons affecting Taiwan: Current understanding and future challenges, B. Am. Meteorol. Soc., 80, 67-80, https://doi.org/10.1175/15200477(1999)080<0067:TATCUA>2.0.CO;2, 1999.

Yang, M.-J., Jou, B. J.-D., Wang, S.-C., Hong, J.-S., Lin, P.-L., Teng, J.-H., and Lin, H.-C.: Ensemble prediction of rainfall during the 2000-2002 mei-yu seasons: Evaluation over the Taiwan area, J. Geophys. Res., 109, D18203, https://doi.org/10.1029/2003JD004368, 2004.

Yeh, H.-C. and Chen, Y.-L.: Characteristics of the rainfall distribution over Taiwan during TAMEX, J. Appl. Meteorol. Clim., 37, 1457-1469, https://doi.org/10.1175/15200450(1998)037<1457:CORDOT>2.0.CO;2, 1998.

Yeh, H.-C. and Chen, Y.-L.: The role of off shore convergence on coastal rainfall during TAMEX IOP 3, Mon. Weather Rev., 130, 2709-2730, https://doi.org/10.1175/15200493(2002)130<2709:TROOCO>2.0.CO;2, 2002. 